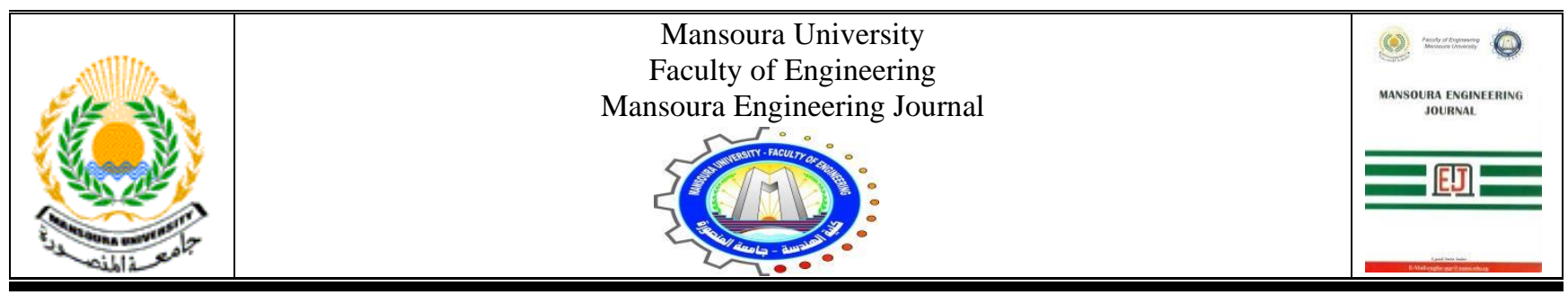

\title{
Assessment of the Urban and Environmental Impact of the Traffic Axes Development Project of Heliopolis
}

\author{
Ahmed Mahmoud saber Mohamed and Ahmed Hosney Radwan
}

\author{
KEYWORDS: \\ (EIA)Environmental \\ impact, (TIA) Traffic \\ impact, Urban impact, Axes \\ of movement, Development \\ of movement axes, Flyovers, \\ Upgrading the road \\ environment.
}

\begin{abstract}
Population growth and urbanization is one of the most important manifestations of modern civilization, this growth has been actively involved in transportation means development(s), and was one of the most serious consequences resulting from the weakness of the efficiency of the current road networks to accommodate those variables, and how to deal with that problem and ways to resolve them. With high considerations of preservation of environmental infrastructure and physical infrastructure. Where some cities today suffer from the lack of proper planning and flour to solve those problems, especially when it concerns the environmental values and civilization of those cities, which led to a big failure or partial inside it, not only on the physical level but also on the environmental and social and economic level and quality of life, as well as the occurrence of psychological disorders and acute health for those who live in those cities, where the research aims to reduce the negative effects resulting from the urban planning solutions and others studied, when developing the axes of movement in cities, which are the values of urban and architectural and ecological, and draw the attention of those concerned with the affairs of urbanization and the development of the importance of sustainable environmental solutions, and alternative bridges, cars, such as Using a vacuum under the earth as important solutions in maintaining the environmental nature and physical infrastructure and the architecture of those cities, combining research among several methods to achieve the objectives of the study, the inductive method survey and discuss the results of a field survey to identify the opinion of a sample of the population and opinion owners and inspiration for designers in the extent of the effect of the scheme of development and bridges on the physical environment and the social study, and gauge the extent of the positive and negative aspects of the new scheme..
\end{abstract}

التخطيط الملائح والدقيق لحل تللك المشكلات، و إهمال الأعتبارات البيئية و

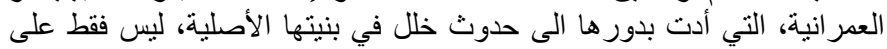

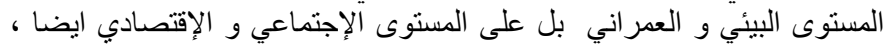

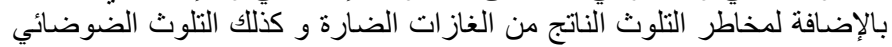

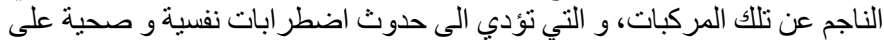

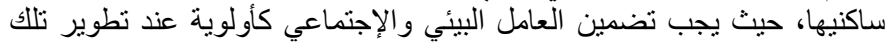
المدن.

$$
1.1
$$

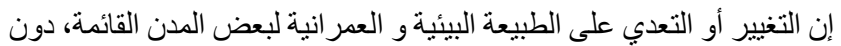

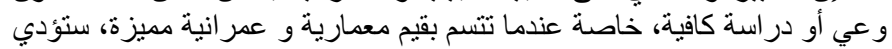

Corresponding Author: Ahmed Hosney Radwan, Associate Professor, Architectural Department, Faculty of Fine arts, Helwan University, Egypt. (Email: Ahosney@gmail.com).

\section{I}

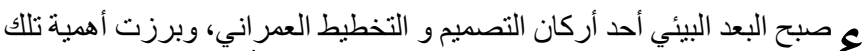

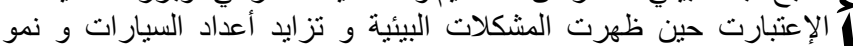

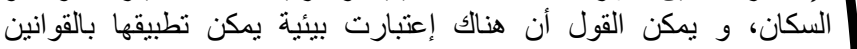

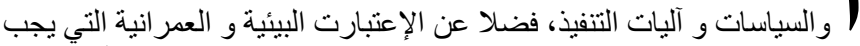

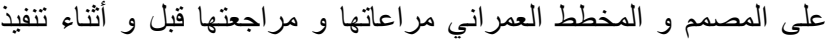

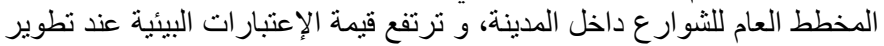

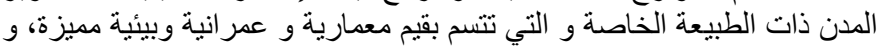

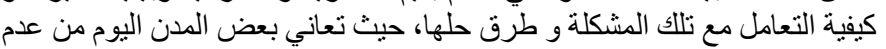

Received: (25 June, 2020) - Revised: (20 October, 2020) - Accepted: (24 October, 2020)

Ahmed Mahmoud saber Mohamed, Associate Professor, Architectural Department, Faculty of Fine arts, Helwan University, Egypt. (E-mail: arch_saber@yahoo.com) 
الأهمية عند إتخاذ الخطوات لتطوير و تتمية أي مجتمع عمر اني مر اعاة الوعاء

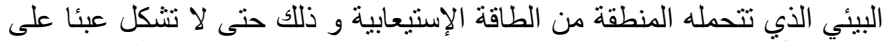

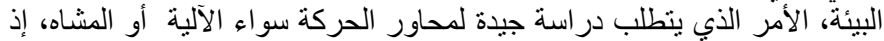

تشتمل منظومة الطرق و وسائل الحركة على الإعتبار ات البيئية الآتية: • الإعتبارت البيئية بطرق السيارة و آثار ها على بيئة المدينة.

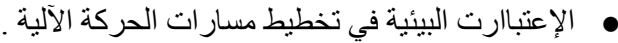
• الإعنبارت البيئية في تخطيط في تشطيط مسار ات المشاه.

1.2 الإعتبار ات البيئية بطرق السيارات و آثار ها على بيئة المدينة:

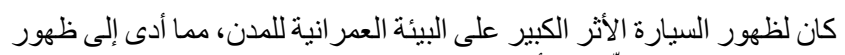

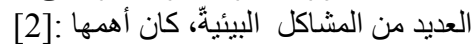

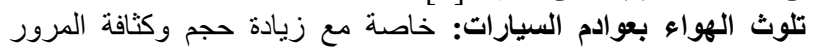

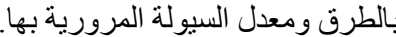

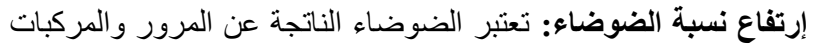

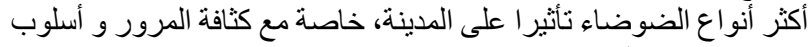
تصميم و إنشاء الطرق. إرتفاع نسبة حوادث الطرق وأمن المشاه: هي مشكلة تحتاج إلى تكثيف

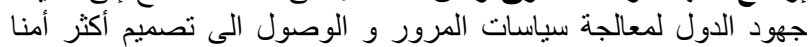

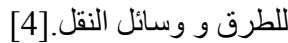
• إهمال المقياس الجمالى و الإنسانى بالمدان إلهان: أدى الإهتمام الكبير بإنشاء

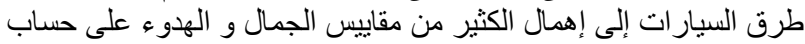

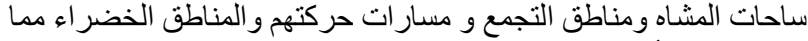

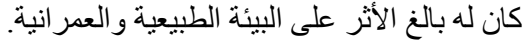

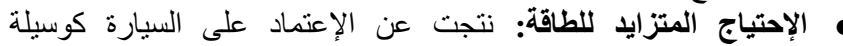

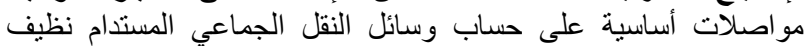

[2] الطاقة، اصنات

الإعتبار ات البيئية في تخطبط مسار ات الحركة:

الإعتبار ات البيئية في تخطبط مسار ات الحركة الآلية:

1.1.2.2 إختيار نو عية الطرق وتكامل الشبكات في المخطط العام من حيث:

توزيع عناصر إستعمالات الأراضي في المخطط العام بحيث تقل مسافة

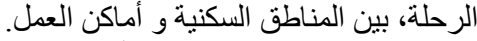

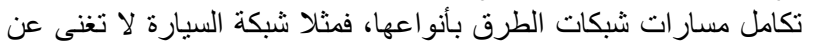

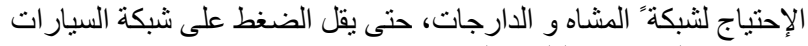

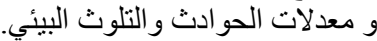

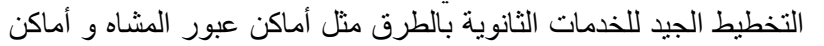
إنتظار السيار ات التي يجب أن يكون لها مخطط منفصل يتم مر اجعته على التى

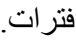

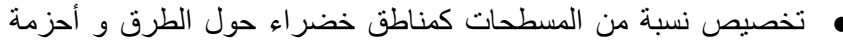

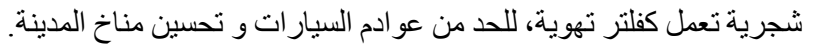

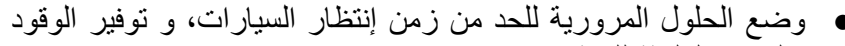
والعو ادم الملوثة للبيئة. • إيجاد مسار ات لحركة المشاه و الدارجات لتشجيع الحركة و و عدم الإعتماد

على وسائل النقل بصفة أساسية. ش (1) التشاه

2.1.2.2 الإرتقاء ببيئة الطرق من خلال سياسات النقل و المرور بالمدينة:

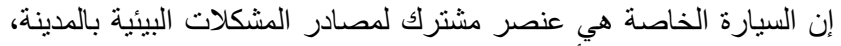

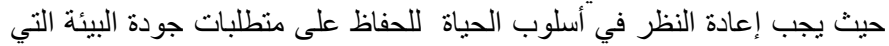

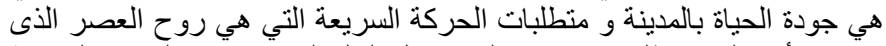

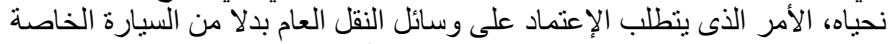

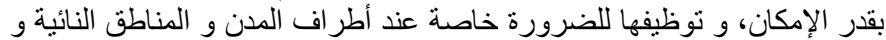

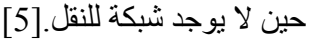

من أهم السياسات الواجب إتباعها لتطوير خدمة النقل العام في المدن :

أ- أولوية سير المركبات النقل الجماعي عن طريق: • تخصيص طرق لسير المركبات بإتجاه سير المرور عن طرئ.
حتما الى مشاكل بيئية و إجتماعية و صحية حادة على قاطنى تلك المجتمعات و ربما ستؤدى الى هجرتها مستقبلا.

2.12

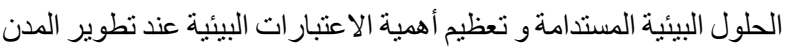

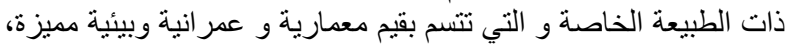

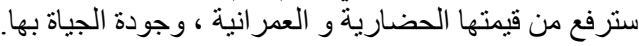

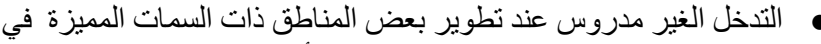

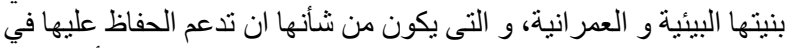

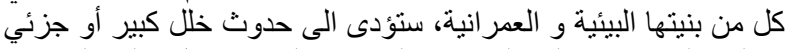

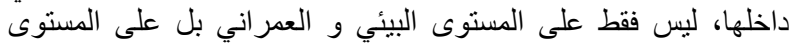
الإجتماعي و الإقتصادي. 3.1 3.1

هالحد من الآثار السلبية عند تطوير محاور الحركة بالمدن القائمة، والتي

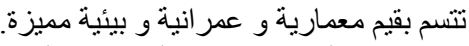

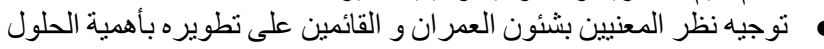

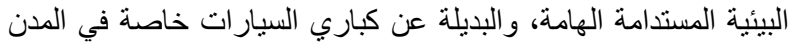
القائمة ذات الطبيعة الخنة الماصة. 4.1

يتناول البحث بالدر اسة و التحليل ثلاث محاور رئيسية:

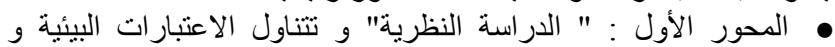

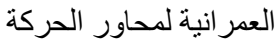
• المحور الثاني: " الدر اسة التطبيقية" و نتناول دراسة التغير ات الحادثة في منطقة الدر استة. • المحور الثالث: دراسة إستقصائية للوقوف على مدى إيجابيات و سلبيات خطة التطوير.

$$
5.1
$$

اعتمد البحث المنهج الإستقر ائي للار اسة النظرية ، و الإستقصائي في الار اسة

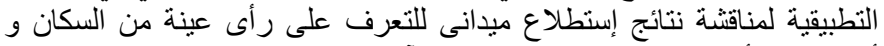

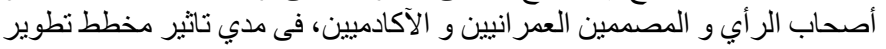

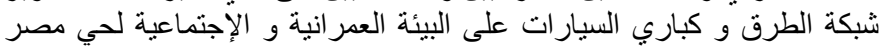

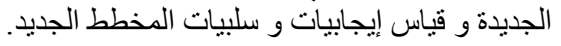

المحور الأول: "الدراسة النظرية" الاعتبارات البيئيةو العمرانية لمحاور الحركة.

\section{: الإعتبارات البيئية لمحاور الحركة $\quad$ II}

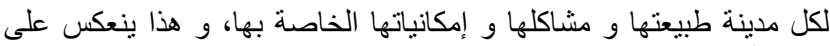

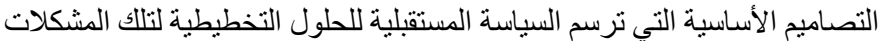

التي تعاني منها، و بما يتلائم و خلق بيئة صحية آمنة. [1]

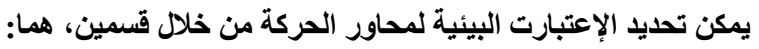

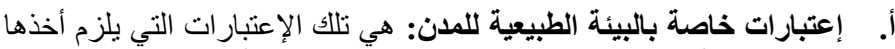

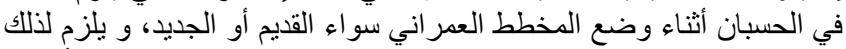

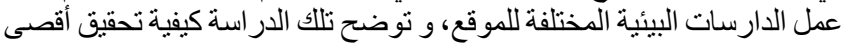

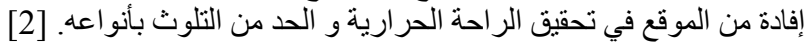

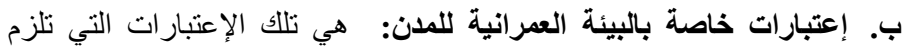

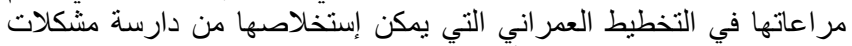

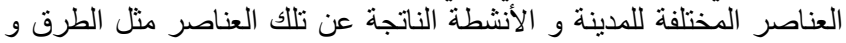

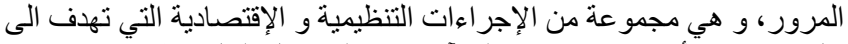

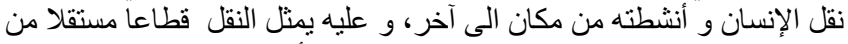

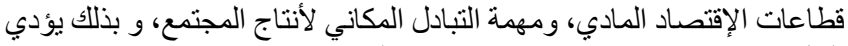

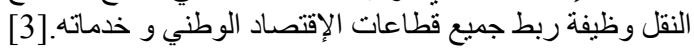

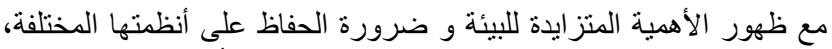

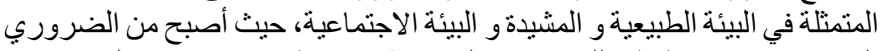

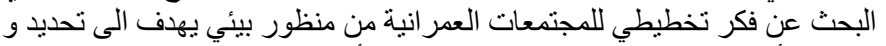

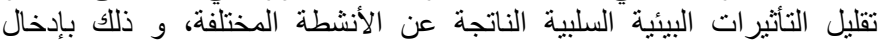

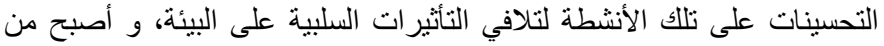




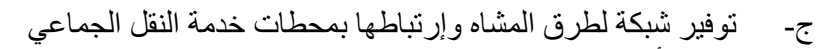

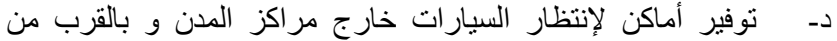

• • تمكين دخول المركبات للمناطق المخصصة للمشاة .

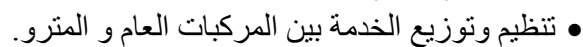

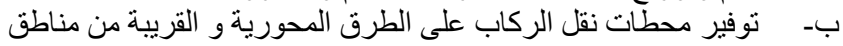
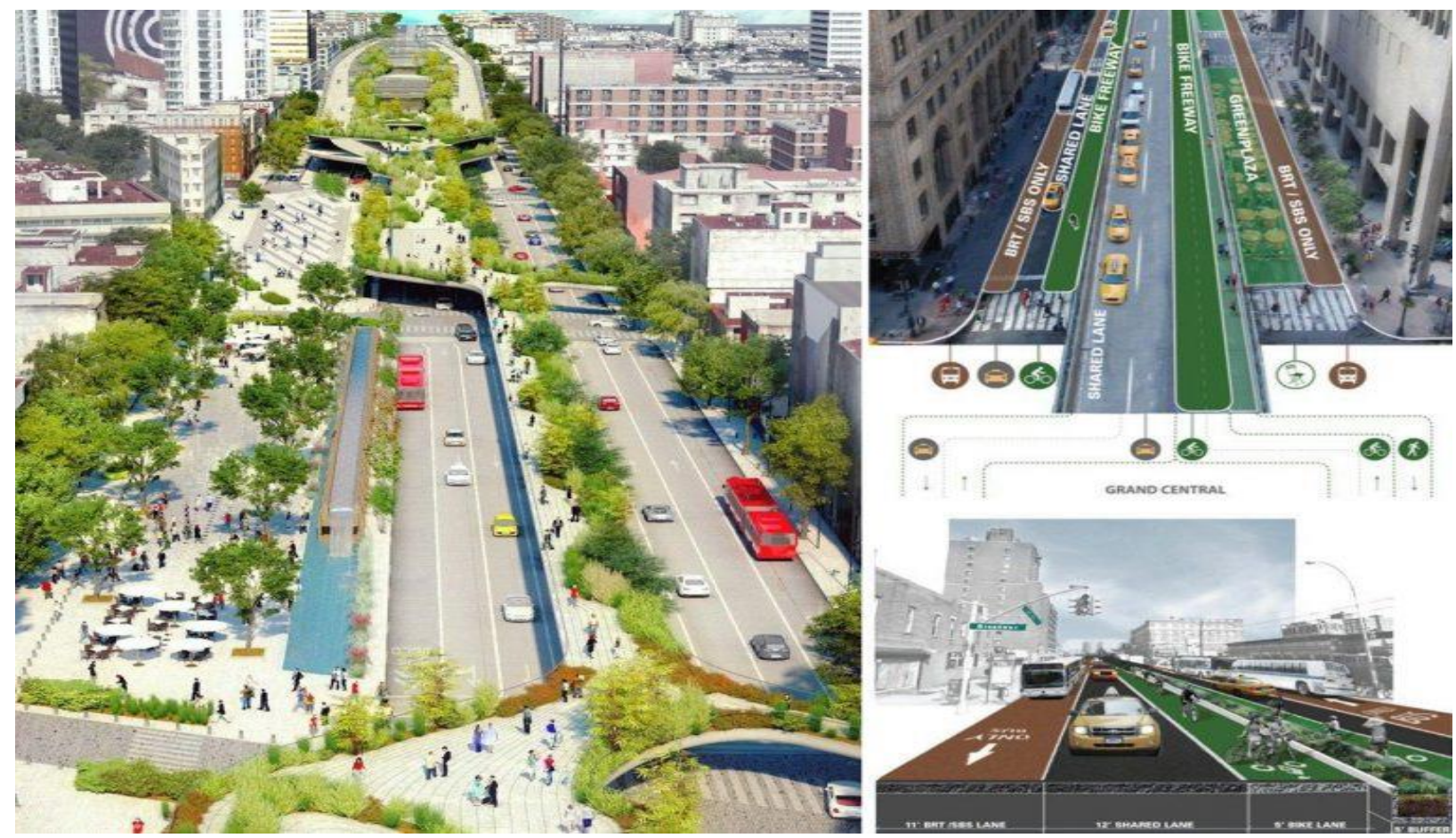

ش (1) حلول لتخطيط الثو ارع الخضر اء الستندامة لتكون أكثر كفاءة وفاعلية مع اعطاء الأولوية للبيئة و الانسان و الكائنات الحية. [32]

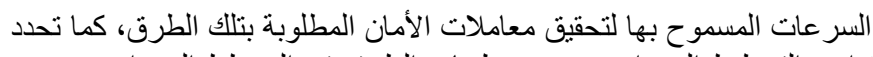

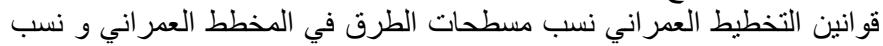
المساحات الخضر اءو و المتنز هات. [1 العبن 3-2 الإعتبارت البيئية لتنطيط مسارات المشاه:

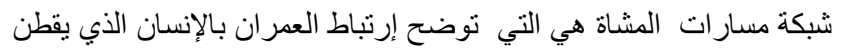

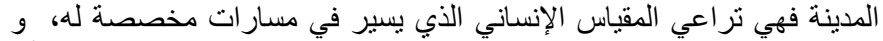

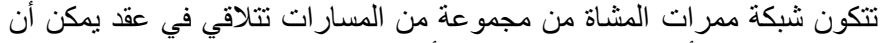

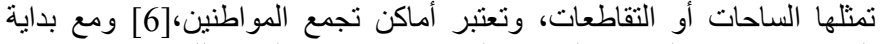

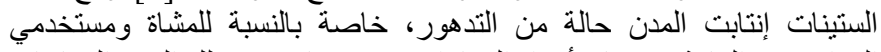

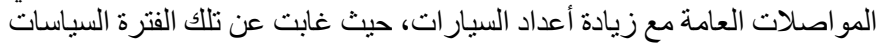

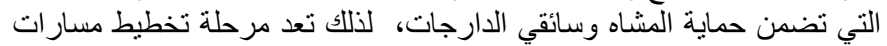

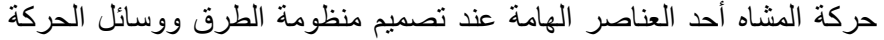
بالمدينة. [2]

$$
\text { 1.3.2 أهمية مسارات وشوارع المشاه: }
$$

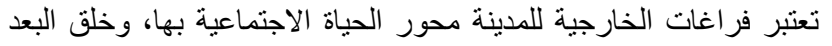

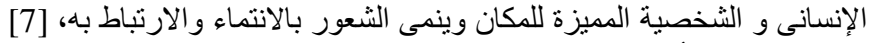

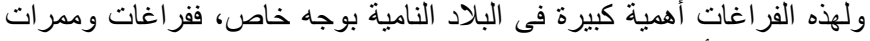

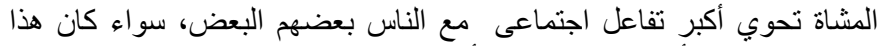

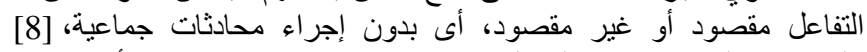

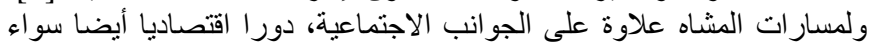

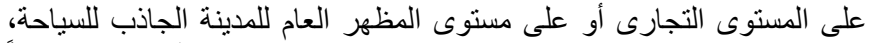

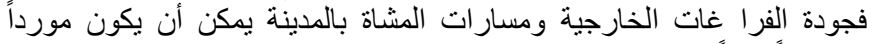

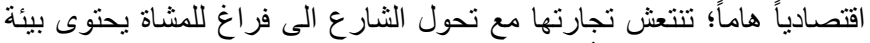
متميزة للراحة او الترفيه أو التسوق داخل الدئنة

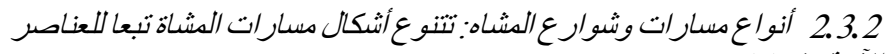
(3) الآتية: ش) (3)

• بمكن أن توجد ممر ات المشاة على مستويات متعددة تعتمد على المناخ السائد و طبيعة البيئة المحيطة.

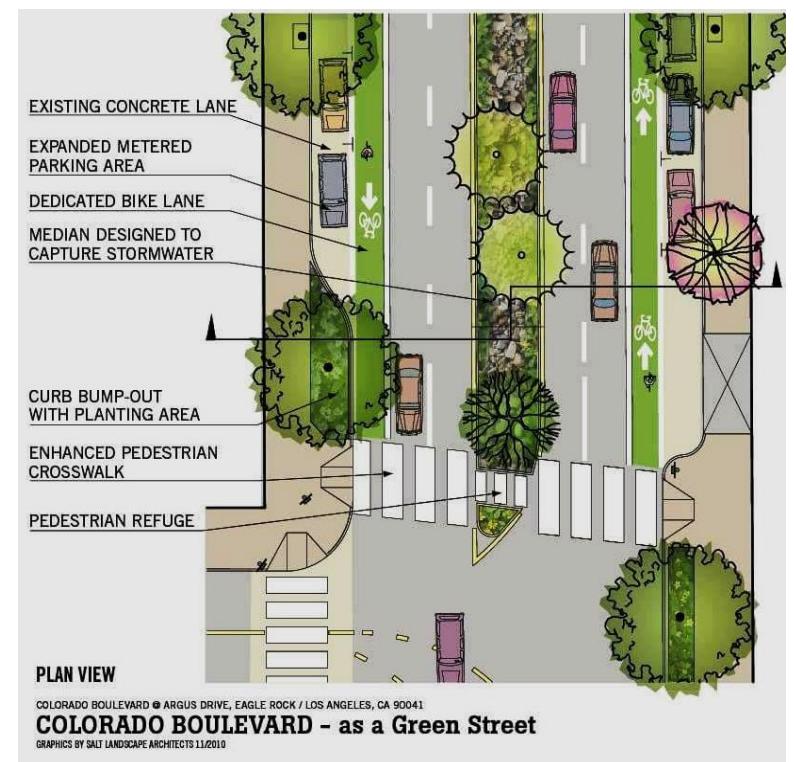

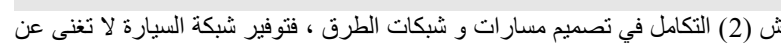

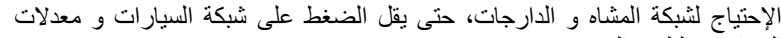

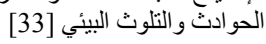

3.1.2.2 دور التشريعات و الإرتقاء ببيئة الطرق :

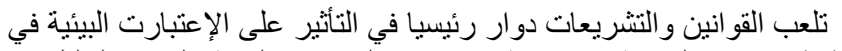

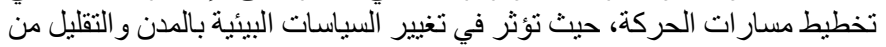

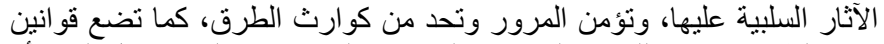

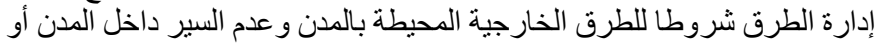
غلق بعض الشو ارع وتحويلها إلى شو ارع للمشاة، كما تضع القو القو انين 
علاقة ممر ات المشاة بمو اقف السيار ات حيث تساهم في نقل المشاة من نهايات الطرق الى المباني. [6] ش (5) المنئة

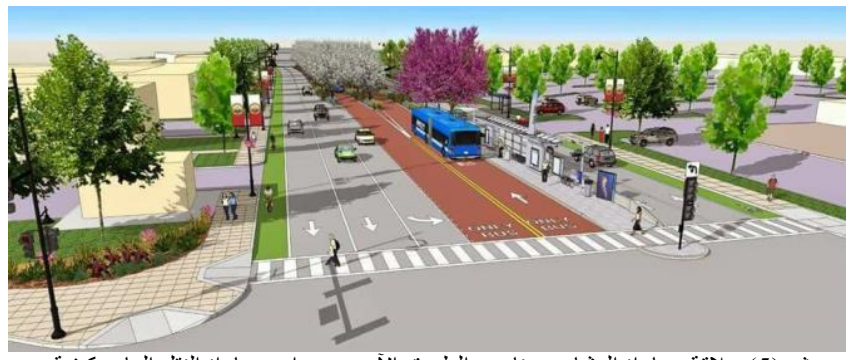

ش (5) علاقة مسار اة المشاه و عناصر الطريق الآخرى سواء بمسار اة النقل العام وكيفية

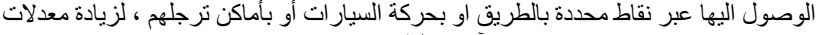

الآمان بالطرق [33

4.2 الإعتبارات البيئة والطابع المعداري والعصراني كقية إقتصادية:

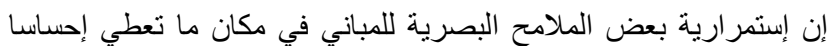

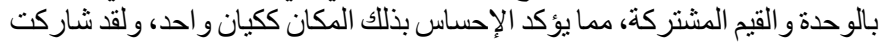

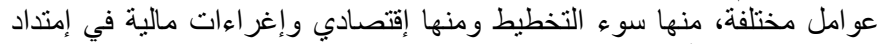

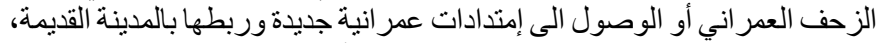

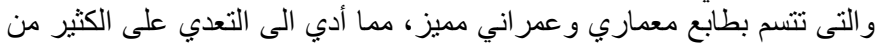

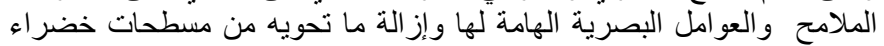

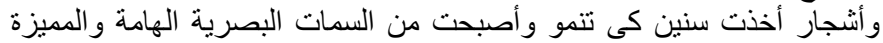

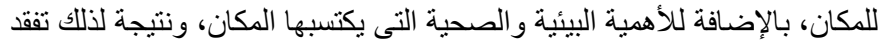

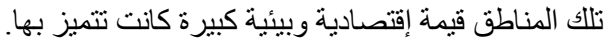

1.4.2 إغفال النو/حي الجمالية:

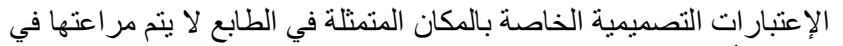

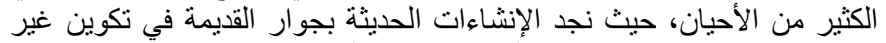

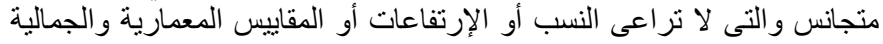
لها، بل تتنافر مع بيئتها العمر انية. لأن الني

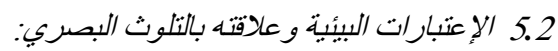

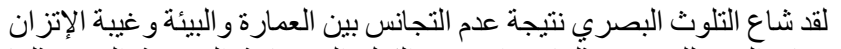

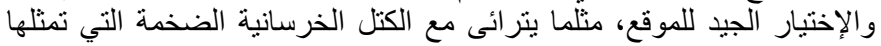

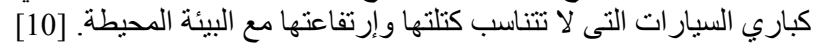

$$
1.5 .2 \text { الكباري والجسور و تأثبر ها البصري على الددينة: }
$$

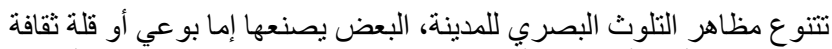

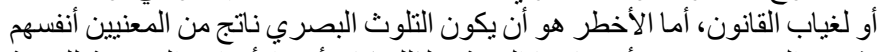

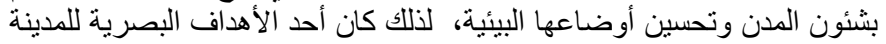

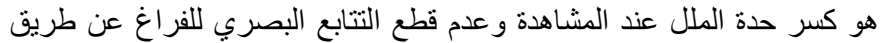

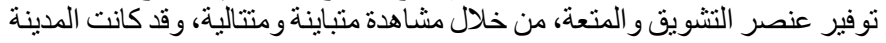

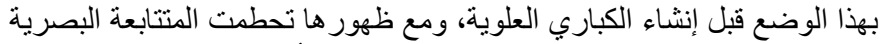

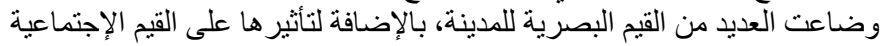

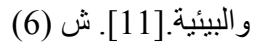

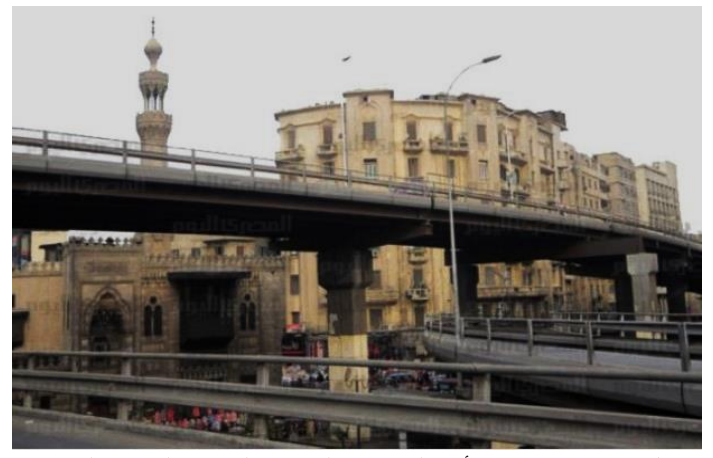

شكل ( 6 ) يوضج مدي نأثير الكباري و الجسور على قطع المتتابعة البصرية

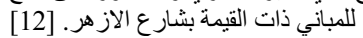

• يمكن أن توجد على المستوى السطحي، بجوار محاور الحركة او المنشآت مع

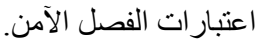

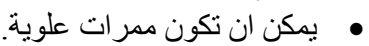

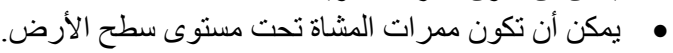

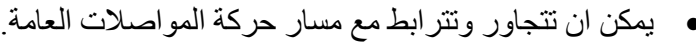

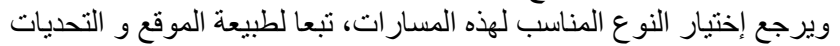

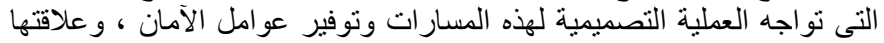

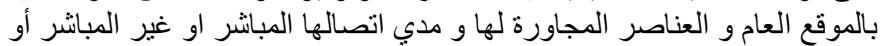

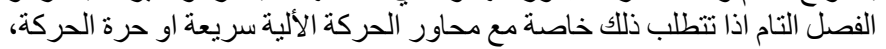

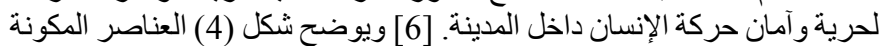
لمسار المشاة و الانشطة الو اقعة عليه.

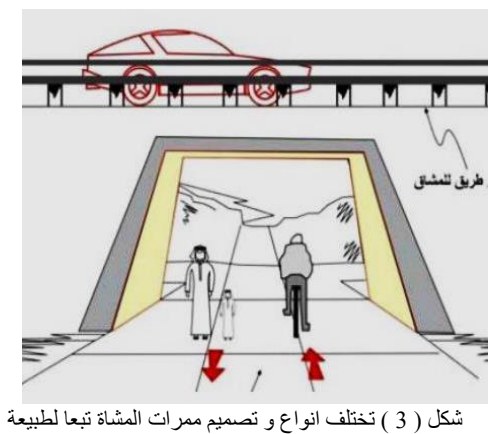

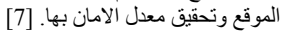

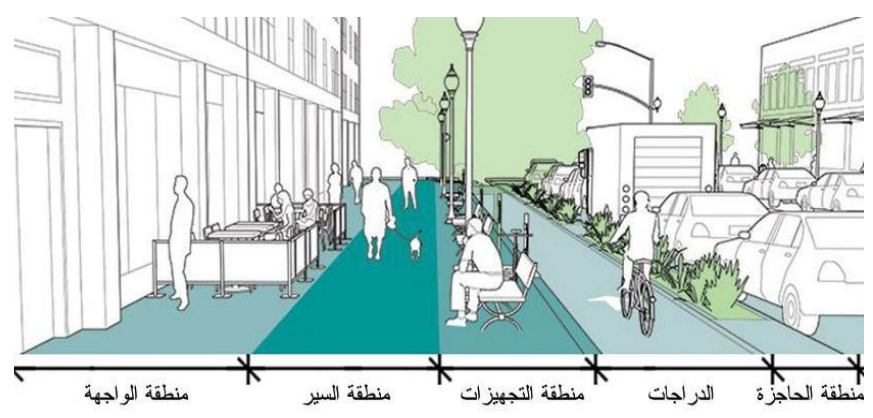

شكل ( 4 ) العناصر المكونة لمسار المشاة و مناطق تفاعل المشاه مع البيئة المحيطة لهو الانشطة الو اقعة عليه. [7]

3.3.2 اتجاهات خلق مسار/ت مشاه بالمدن الدندحمة:

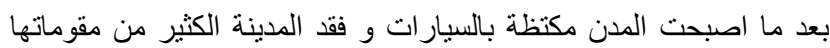

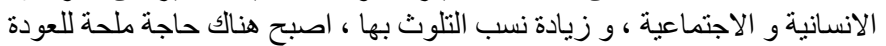

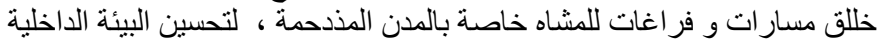

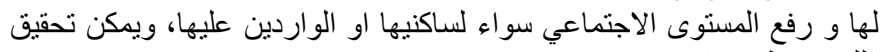

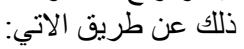

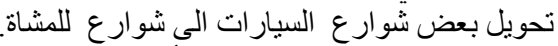

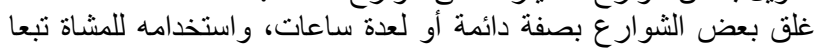
لبرنامج زمنى معلن. تحويل مسار السيارات الى أحد الطرق البديلة، وإمكانية ربط المبان الطريق

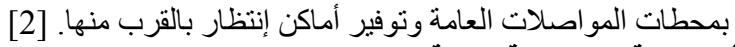

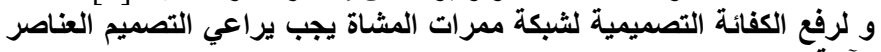

ممر ات المشاة و أنو اعها و عروضهاو منبع و مقصد هذه الممر ات، و سهولة الوصول لشبكة مسار ات المشاة أنساة.

ير اعى تصميم الرصيف وليف و أماكن الجلوس بأبعاد تحقق الر احة للمستخدمين، وخدمات ذوي الاحنياجات الخاصة. تعزيز المظهر الخارجي وتحقيق صورة الاحئه الخاصة بصرية جيدة ومناطق التجمع عليه.

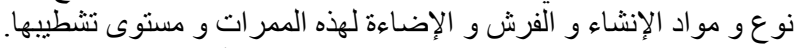

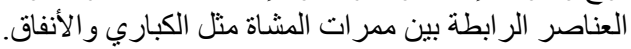

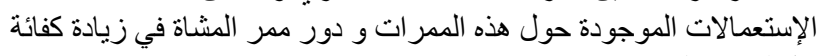

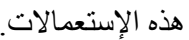


أسباب متعلقة بمتخذي القرار: تضارب القرارت، وتجاهل رأي العلماء

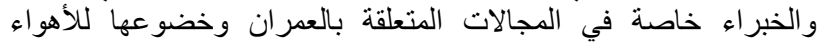

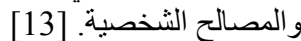

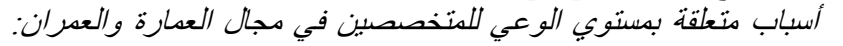

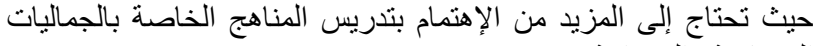
المعمارية والعمر انية المئ.

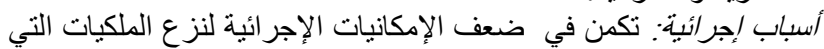

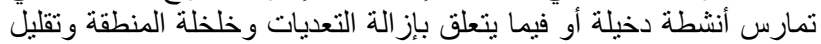

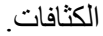

أسباب سياسية: التباطئ في القرارات التي تستهدف حل مشاكل المنطقة،

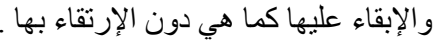

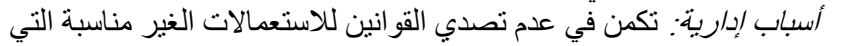

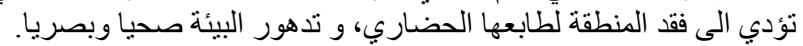

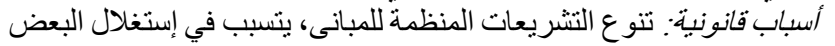

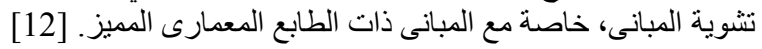

المحور الثاني: "الدراسة التطبيقية" الأثر البيئي والعمراني لخطة تظوير منطقة مصر الجديدة.

1.3 المصاحبة لها.

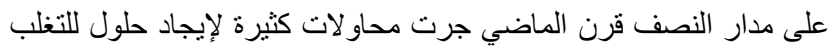

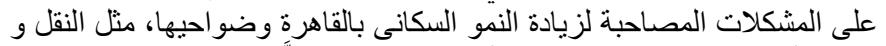

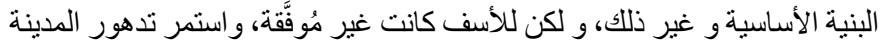

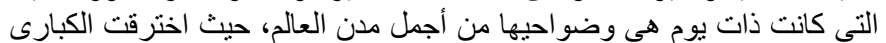

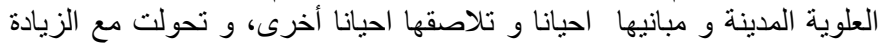

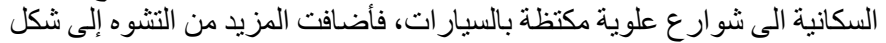

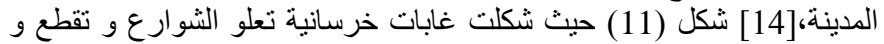

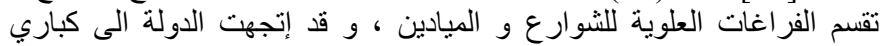

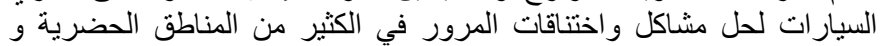

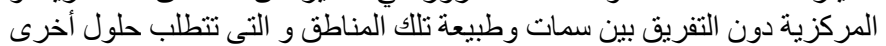

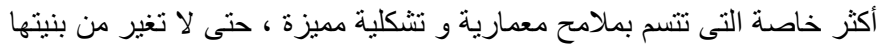

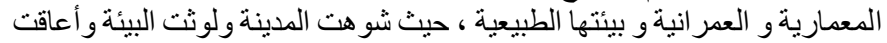

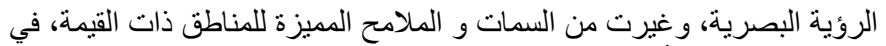

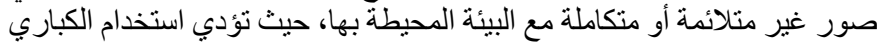

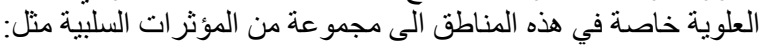
تقسيم الفر اغات و تقليل الإستمتاع بالمتنابعات البصن البصرية.

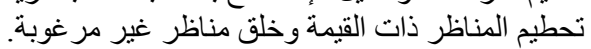
هدم المفهوم القديم للميدان وتتشويه المباني حوله خاصة الفئ التاريخية و ذات القيمة. انعدام الخصوصية للمباني المجاورة لها. [15]

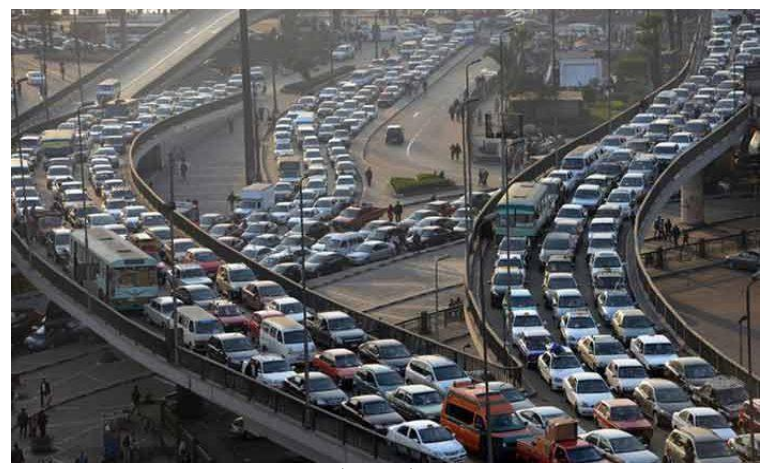

شكل ( 11) الكثافات المرورية أعلى و أسفل كوبري 6 اكتوبر . [34]

2-3 الخلفية التاريخية لمصر الجديدة:

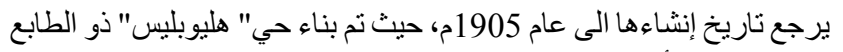

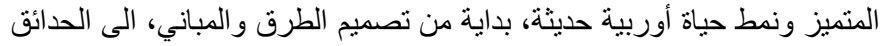

2.5.2 أخطار التلوث البصري:

تكمن خطورة التلوث البصري في إرتباطها بالدرجة الأولى بفقد الإحساس

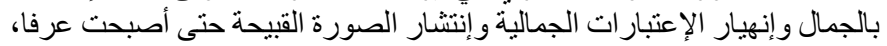

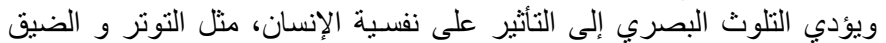

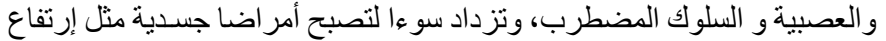

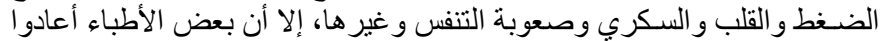

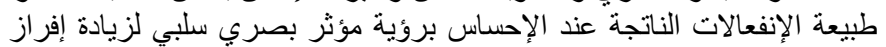

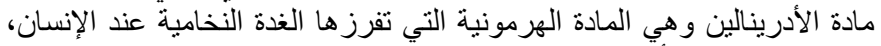

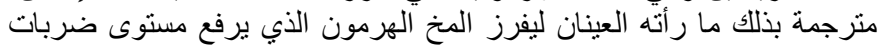

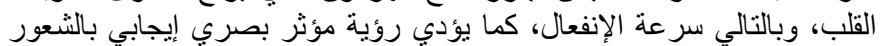

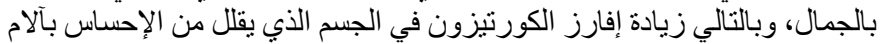

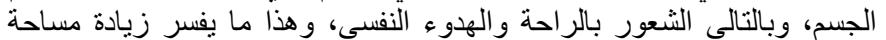
العدوانية و السلوكيات الحادة، خاصة المناطق المكنة المكنة بالسكان. [12]

3.5.2 مصادر التلوث البصري:

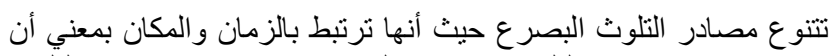

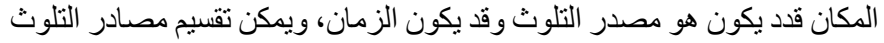

• التلوث الذاتي: يكون مصدر التلوث ذاتيا عندما يتسبب الثيء ذاته في إحداث

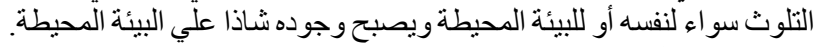

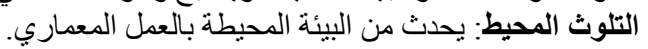

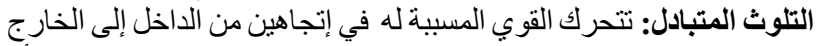

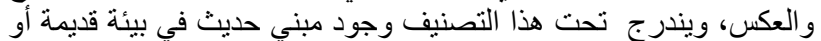
تاريخية لها طابع حضاري مميز. [10]
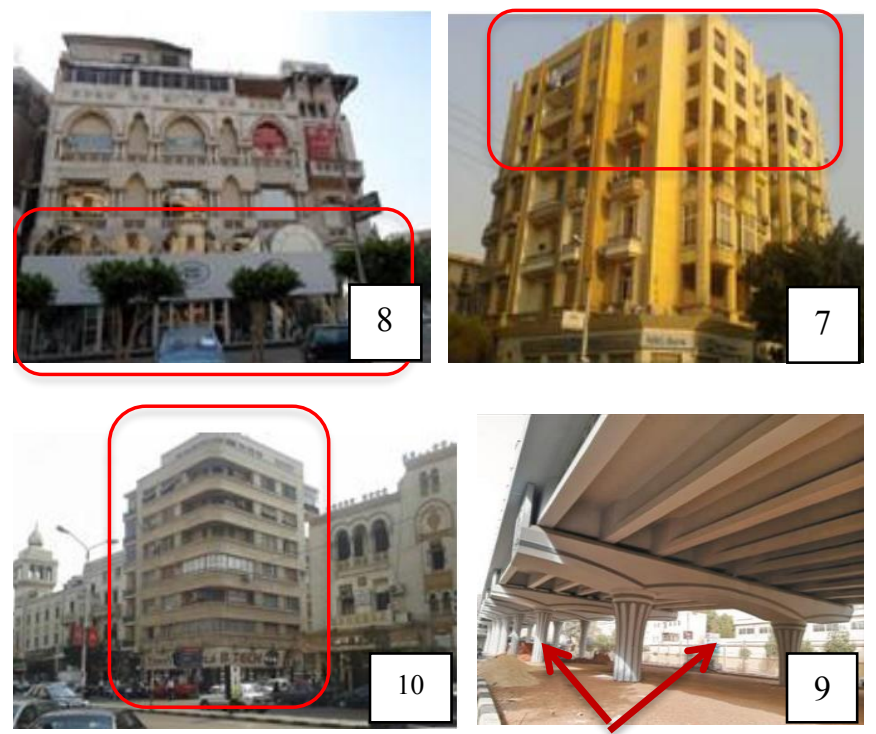

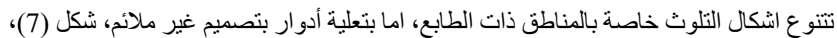

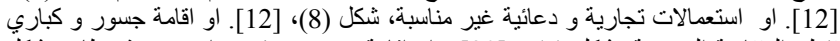

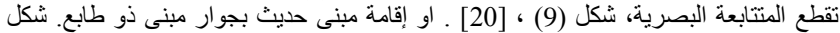

[12] (10)

4.5.2 أسباب التلوث البصري: تتنوع لأسباب يمكن إختصار ها فى التالى:

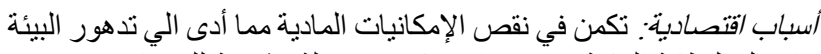

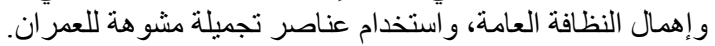

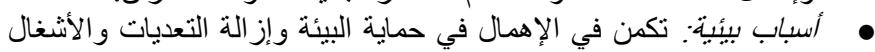

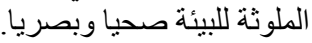

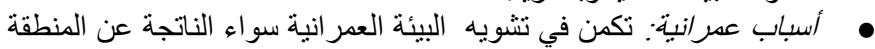

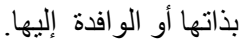
أسباب ثقافية : تكمن في فقد الوعي و الحس الجمالي في المحافظة علي البيئة

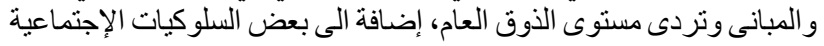

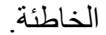



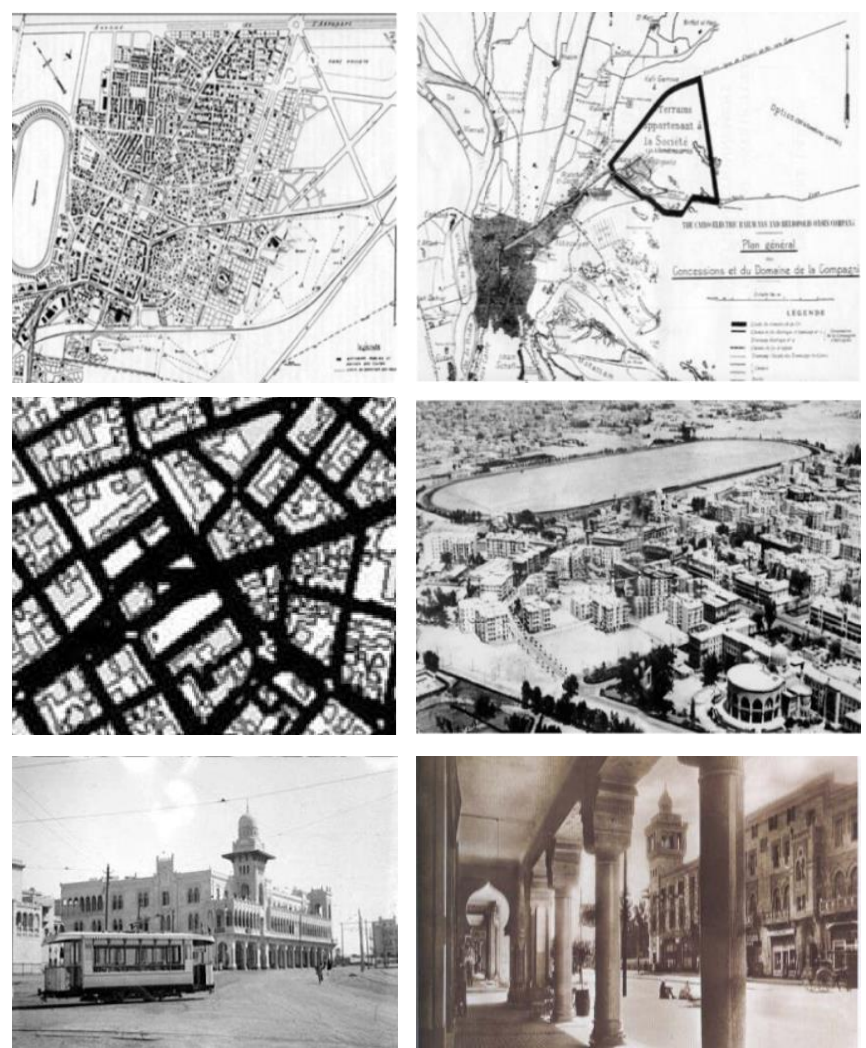

شكل ( 12 ) يوضح موقع مصر الجديدة" هليوبليس "بالنسبة لددينة القاهرة و شكل النسيج

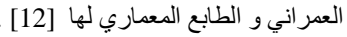

$$
\text { 2.4.3 الطابع العام و الملادح المميزة للمدينة: }
$$

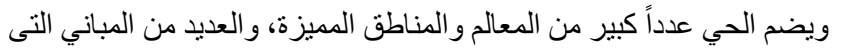

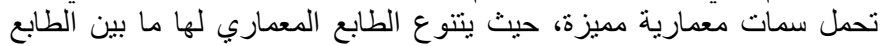

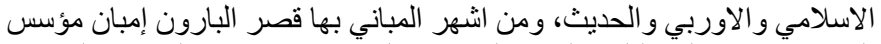

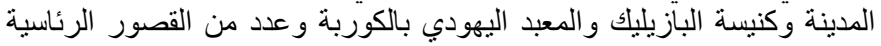

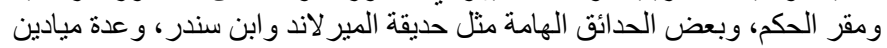

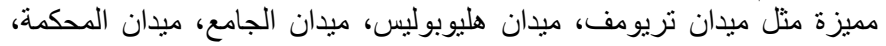

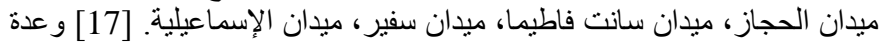

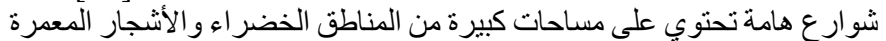

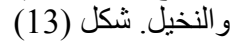

3.4 .3 تنفيذا للخطة القو مية الجديدة للطرق، وتطرئرة وتطوير محاور الحركة التى تبنتها الدولة،

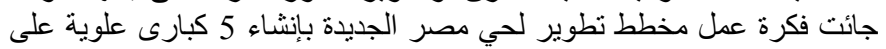

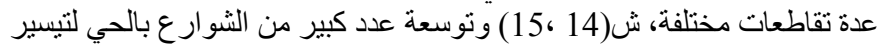

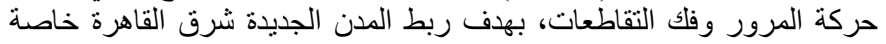

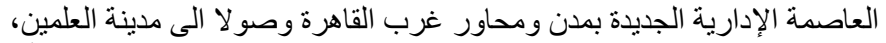

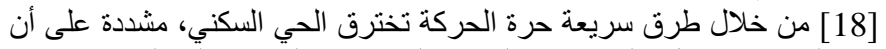

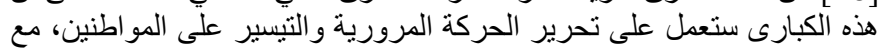

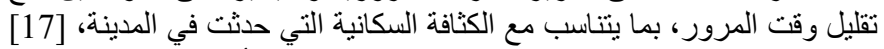

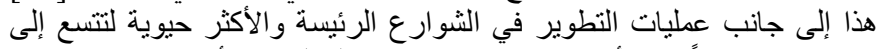

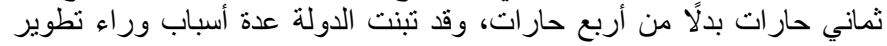

محاور الحركة بمصر الجديدة هي: [19]

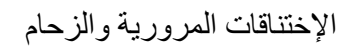

الخفائر المالية بسبب الإختنافقات المرورية إرتفاع معدل التلوث البيئي ـ الإنيات

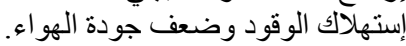

صعوبة ربط مصر الجديدة بمحيطها لعدم وجود محاور مرورية حرة في

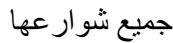

ضعف قدرة إستيعاب شبكة الطرق الرئيسية والثقاطعات لحجم الحركة

$$
\text { المرورية. }
$$

الو اسعة و المساحات المفتوحة، وتم إنثاء خط سكة حديد وخطوط تر ام تربط المدينة

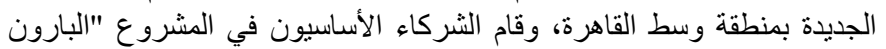

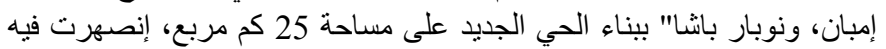

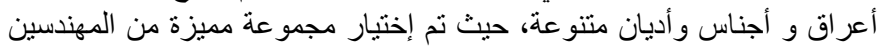

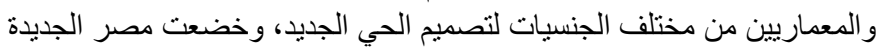

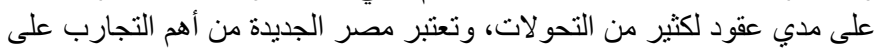

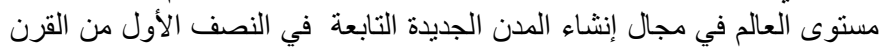

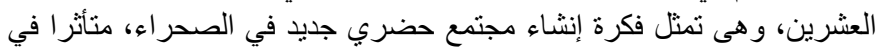

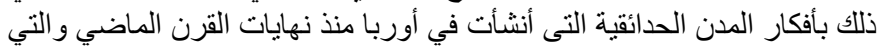

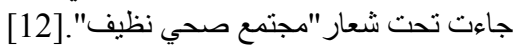
3.3 أسباب إختبار الدنطقة:

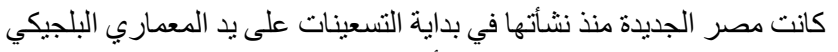

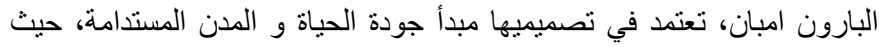

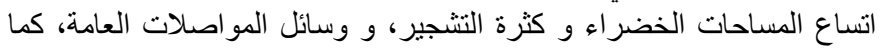

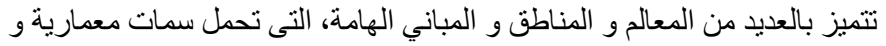

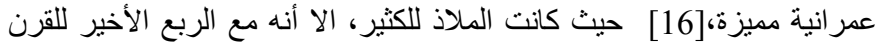

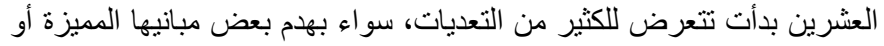

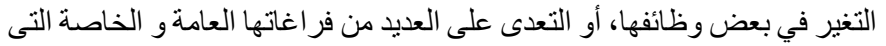

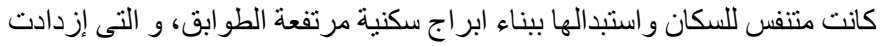

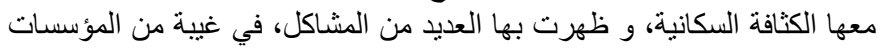

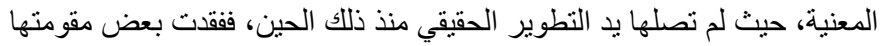

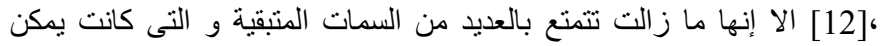

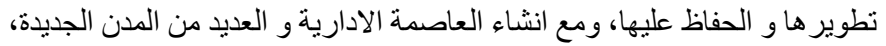

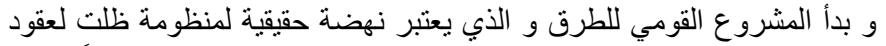

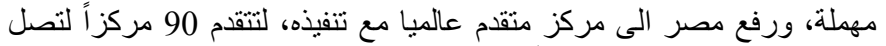

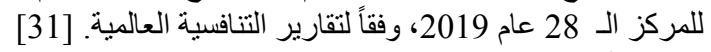

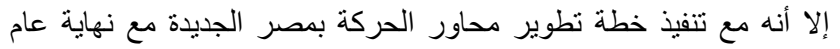

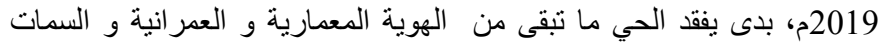

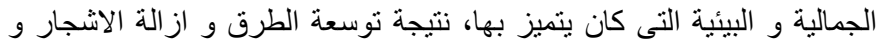

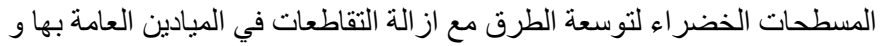

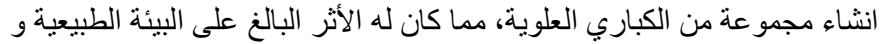

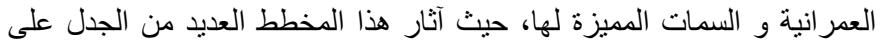

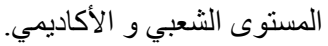

4.3 مشروع تطوير محاور الحركة بنطقة مصر الجديذة: 1.4 .3 الفكر التخطيطي و الطابع العام للمدينة:

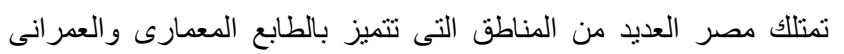

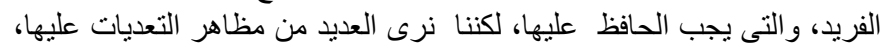

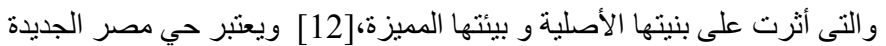

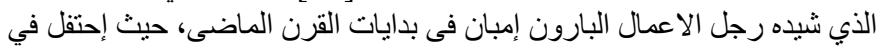

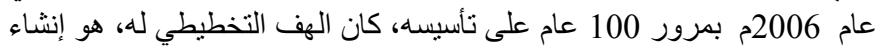

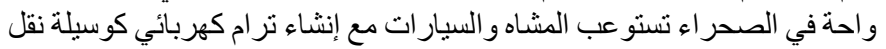

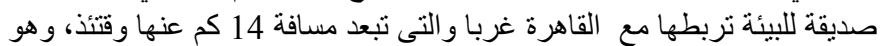

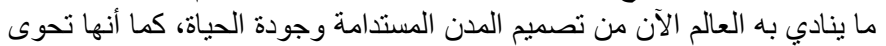

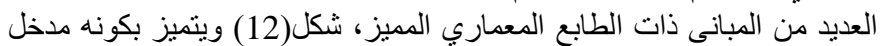

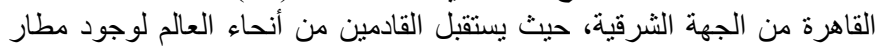

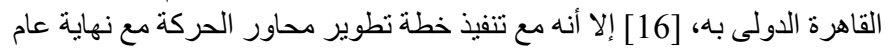
2019م، بدى يفقد الحي الهوية المعمارية والعمر انية والسمات الجمالية والبيئية

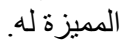




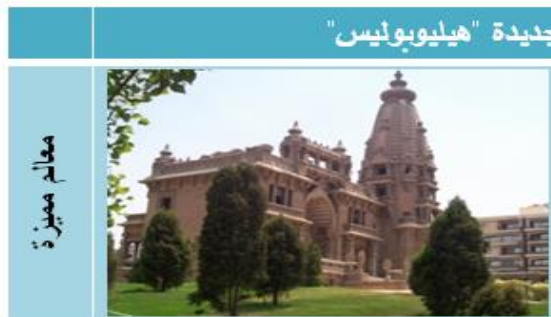

قصر مؤسس المدينة البارون امبان

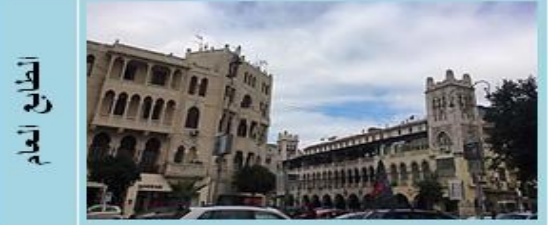

الطابع الاسلامي لعمارة مصز الجديدة
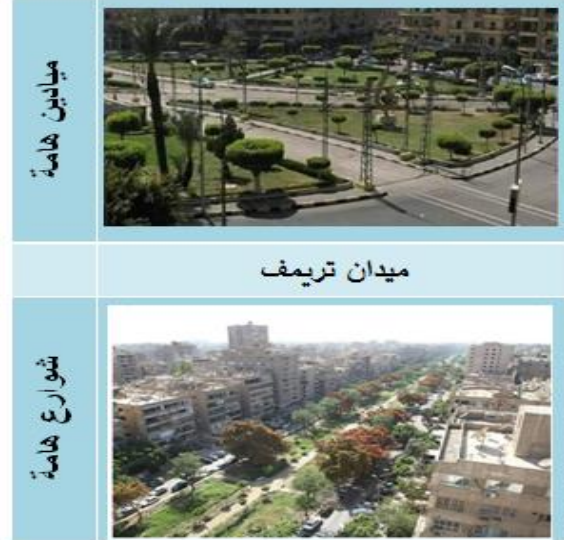

شارع عبد العزيز فهمي

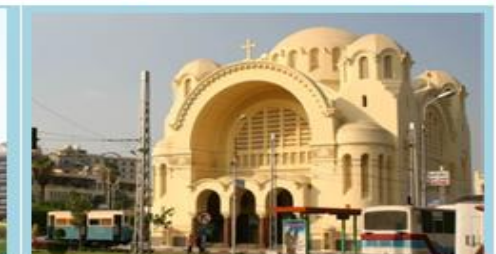

كنيسة البازبيك

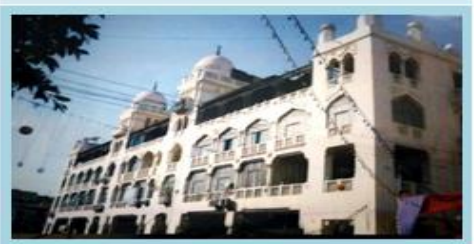

القباب و العقود لعمارة مصر الجديدة

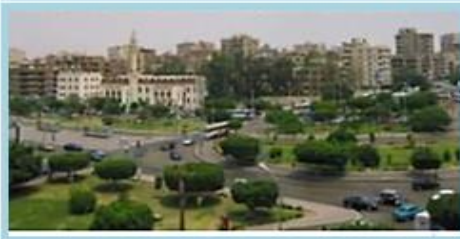

ميدان الحجاز

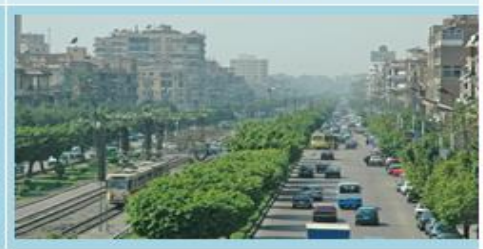

شارع عثمان بن عفان

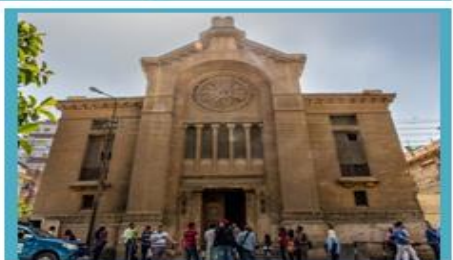

المسبد اليهودي

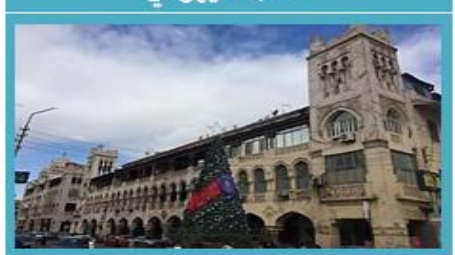

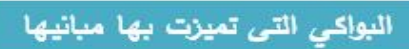

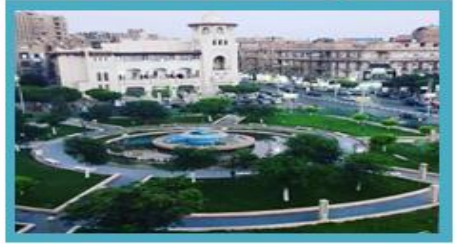

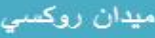

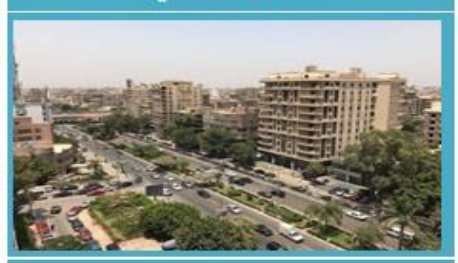

5, औill \&lk

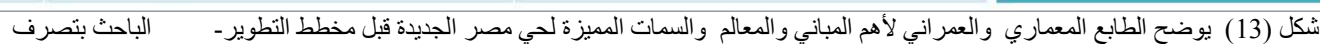

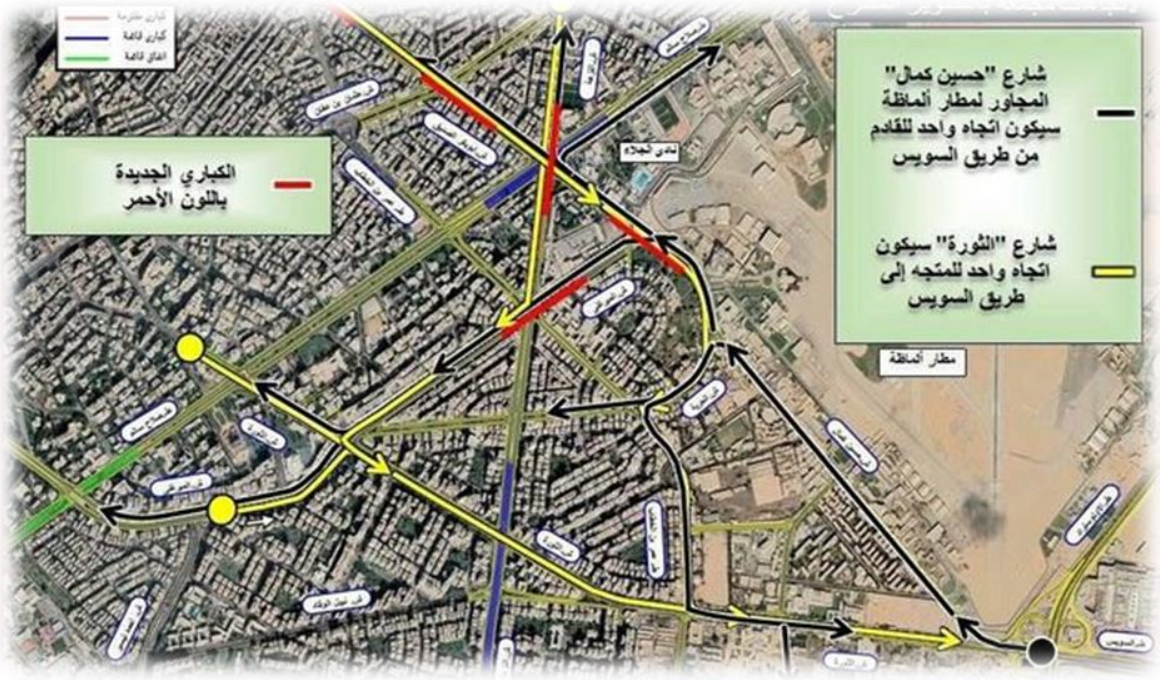

خريطة تطوير محاور الحركة و كباري السيارات

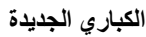

الكباري قايمة الكائمة

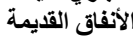

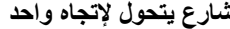

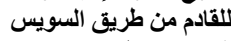

شُارع يتحول باتجاه واحد

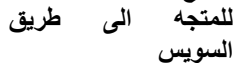

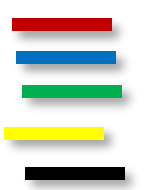

شكل (14) يوضح خريطة تطوير محاور الحركةو كباري السيارات الجديدة بمنطقة الدراسة. [20] 

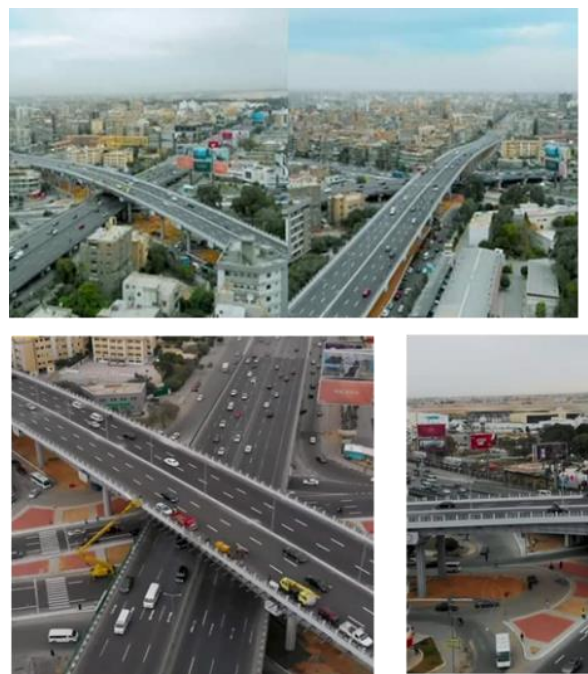
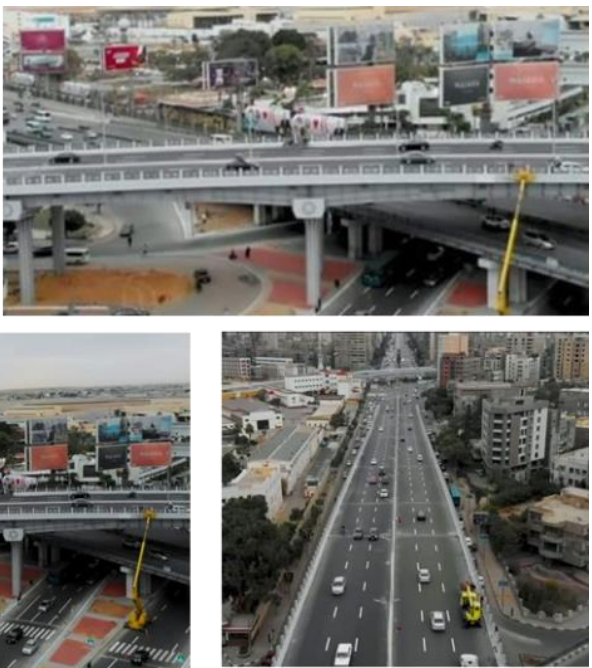

كباري السيارات و توسعة محاور الحركة بعد الانثاء. • كوبري تقاطع الميرغنى مع شارع أبوبكر الصديق،

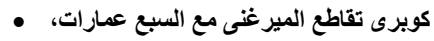

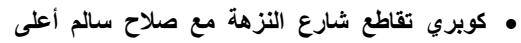
كوبرى الجلاء. • عوبري تقاطع شارعى أبوبكر الصديق مع عثمان بن عفان.

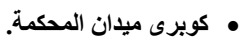

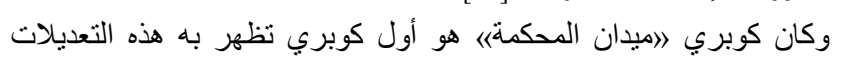
الجمالية.ش (17) - (17).

أما عن الأشجار المقامة سابقًا، نُقِلَت بعضها لحين إنتهاء المشروع، ولهذا

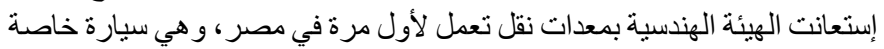

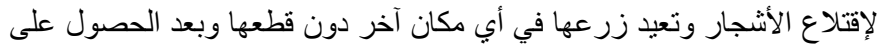

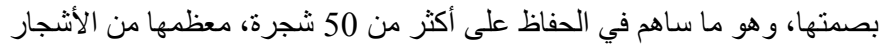

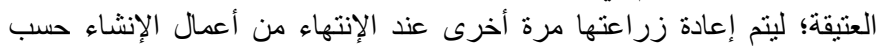
تصريح وزيرة البيئة، إلا أن المهدر أكثر بكثير من الذي تم نقله. [18] ش (18) الأنهاء الأنشاء

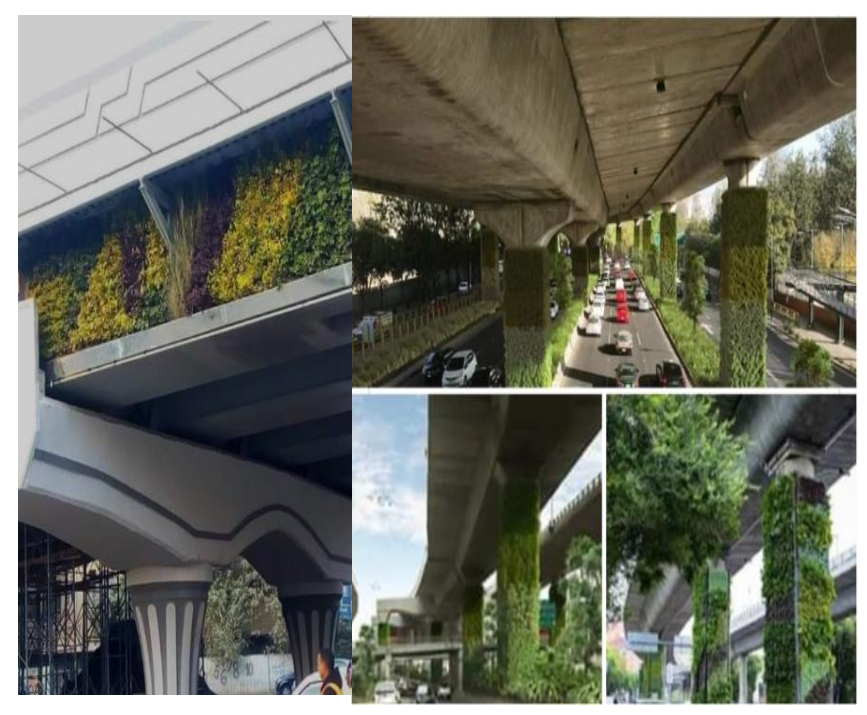

شكل (17) يوضح المعالجات البيئية و الجمالية لكباري السيارات المقترحة من اليمين و ما تم

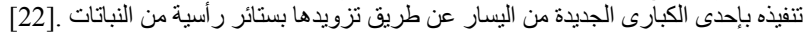

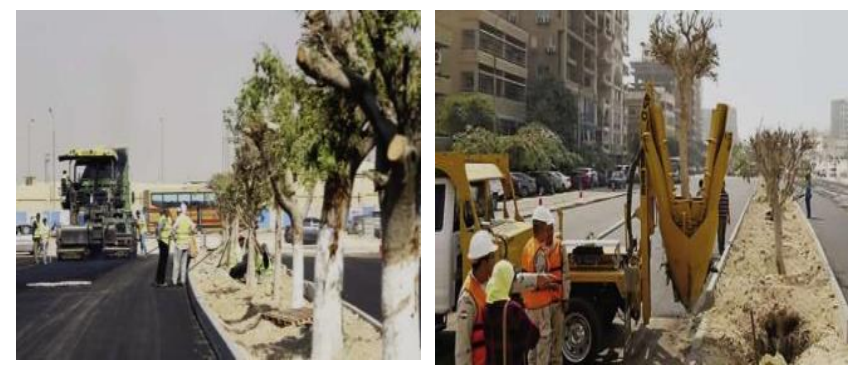

شكل (18) يوضح طريقة إزالة و نقل بعض الأشجار القديمة من مو اقعها.[23].
على الجانب الآخر نرى أن العديد من الدول قد بدأت في تعزيز الجوانب البيئية

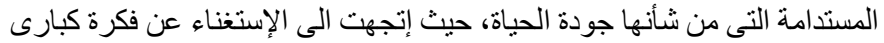

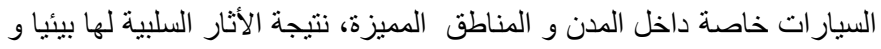

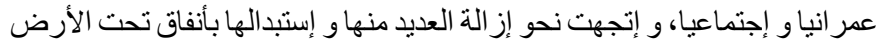

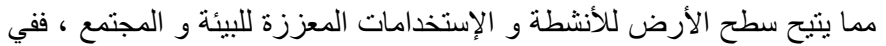

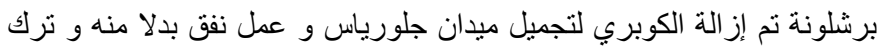

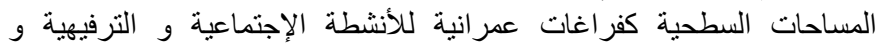

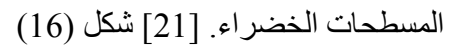

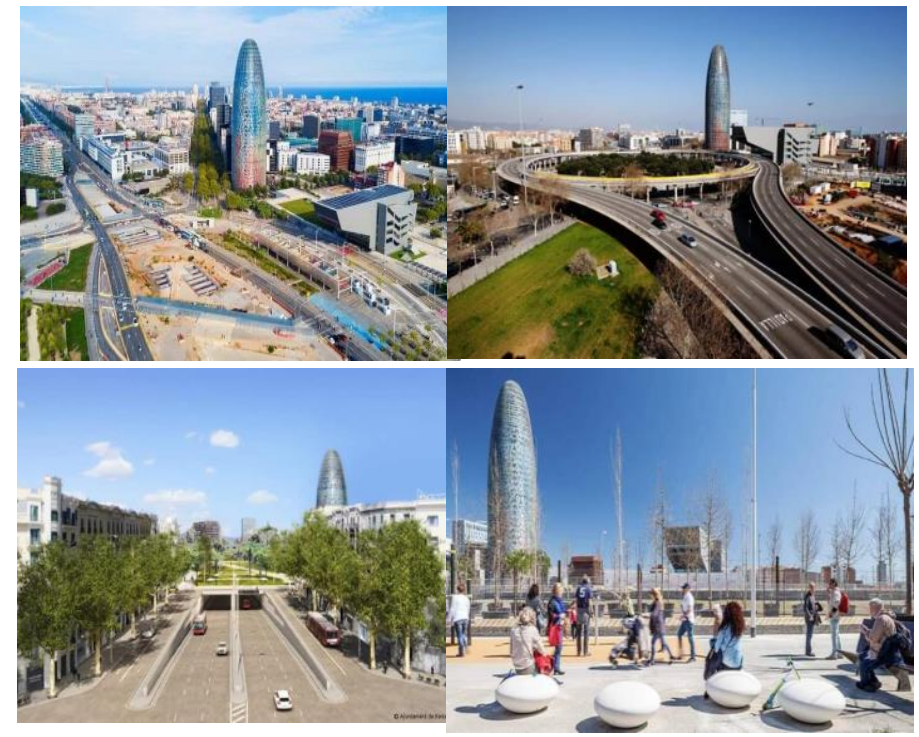

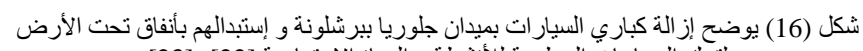

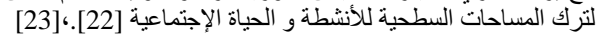

\section{4 .3 الجوانب البيئية و الجمالية في خطة التطوير:}

لم تقتصر الكباري على تسهيل حركة السير، و إنما عملت الدولة على على تداخل

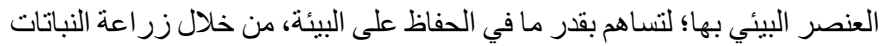

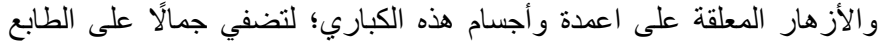

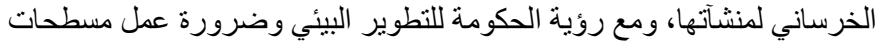

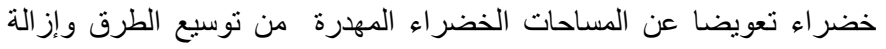

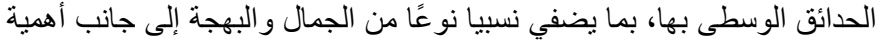

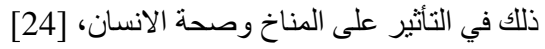


تنظم قو انين البناء و التشريعات الخاصة بالبيئة العمر انية شكل البيئة المبنية،

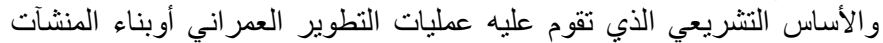

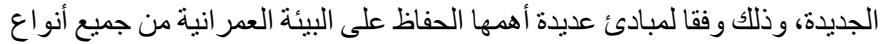

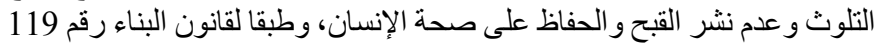

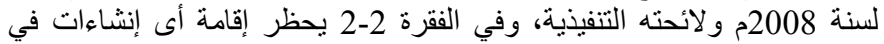

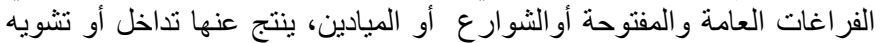

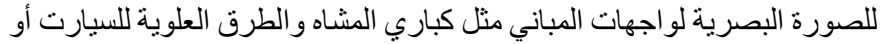

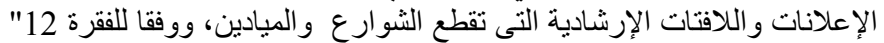

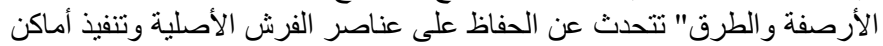

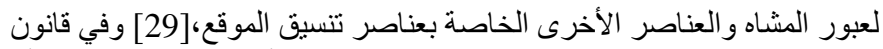

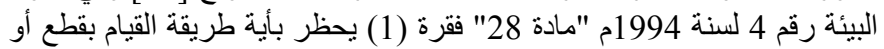

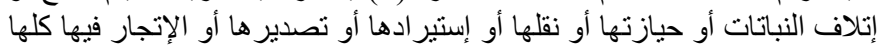

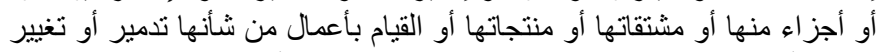

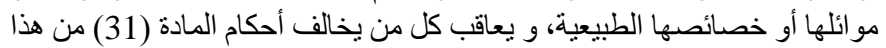

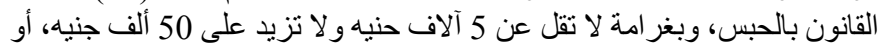

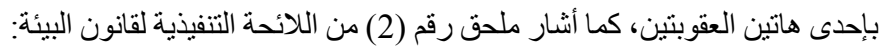

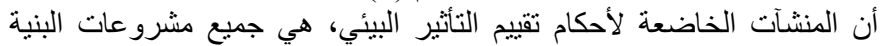

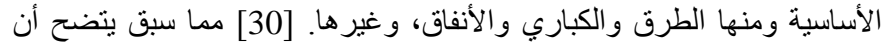

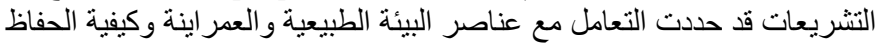

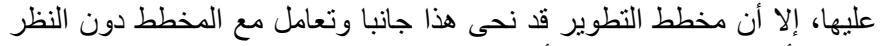

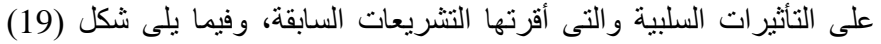

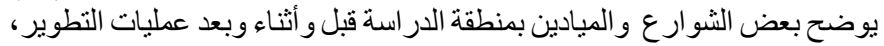

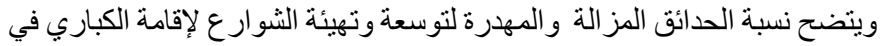
التقاطعات
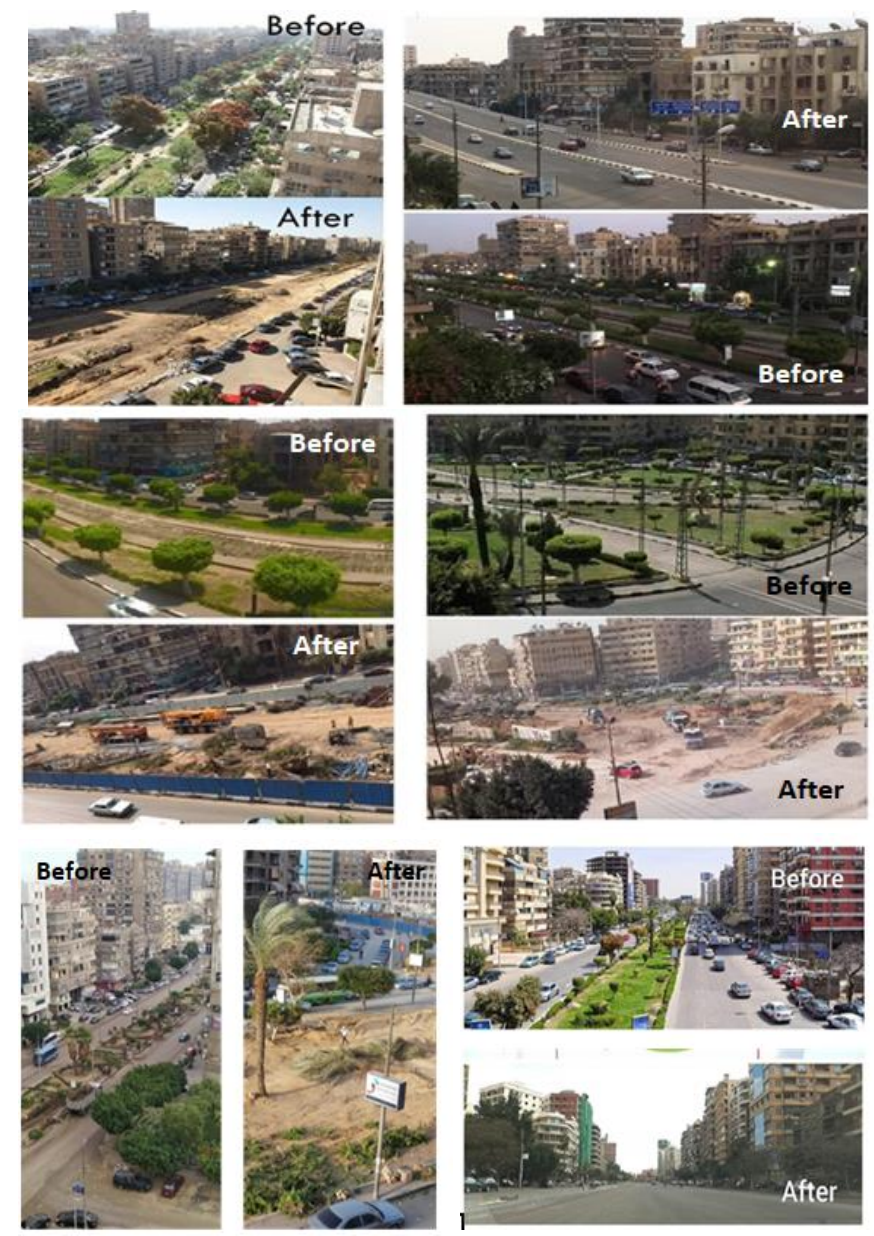

5.4.3 الأثر البيئي و العدراني لمخطط تطوبير محاور الحركة بنطقة مصر

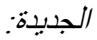

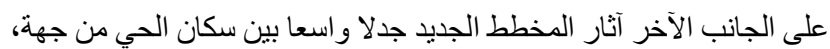

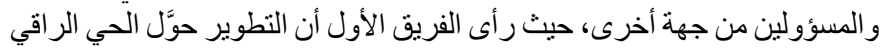

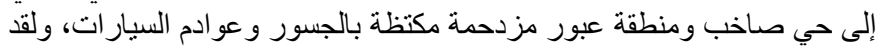

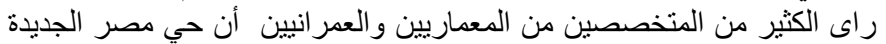

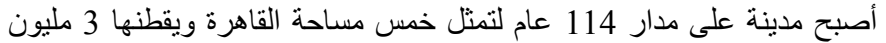

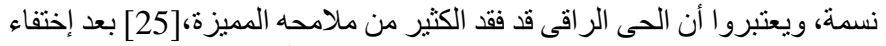

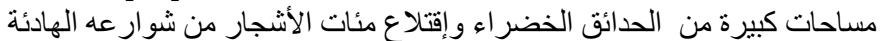

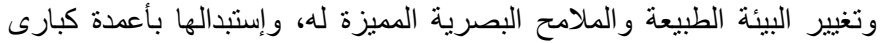

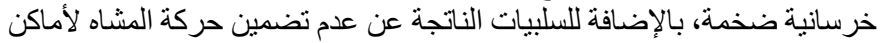

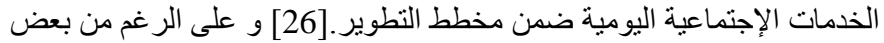

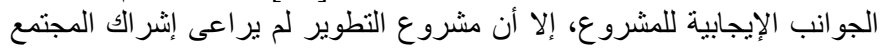

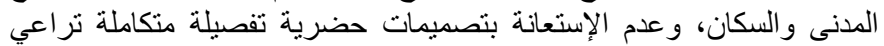

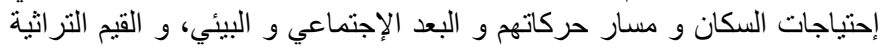

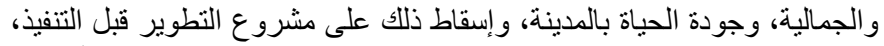
حيث تم التخطيط لمحاور حركة واسعة وسريعة في مناطق سكنية، دون الأخذ في في الإني

الإعتبار الكثير من المعايير التصميمية، مثل:[27 حمنة تدرج المسار ات من أرصفة للمشاة.

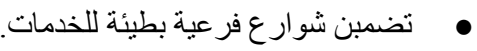
• الحفاظ على البيئة الطبيعة الموجودة.

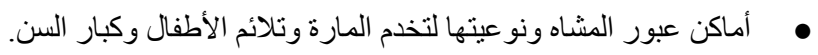

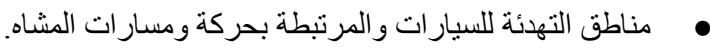
الصورة الذهنية و البصرية للمدينة.

هذا بالإضافة الى أن الطرق قد تسببت في إلغاء نقاط إلتقاء السكان مع وسائل

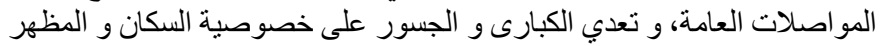

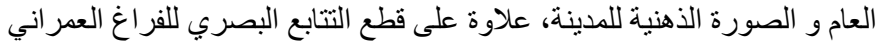

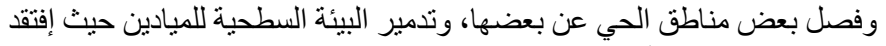
المشروع المبادئ الأساسية لنظريات التخطيط العمراني المستدام التى تتضين التصن

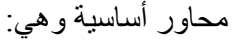

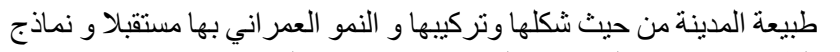
الطرق و تخطيط المرور و الخدمات الإجتماعية لسكانها.

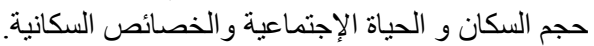

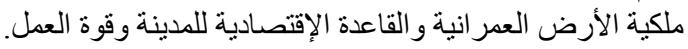

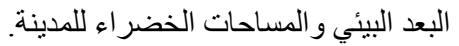

1.5.4.3 تأثبر مخطط التطوير على البيئة الطبيعية بالحي:

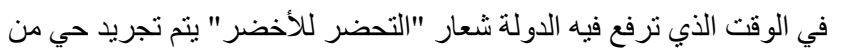

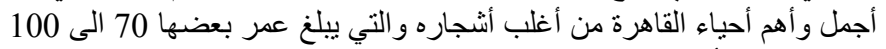

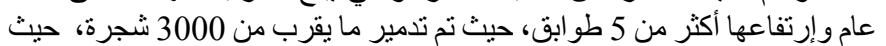

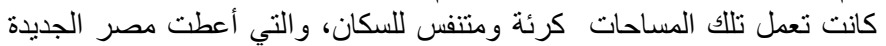

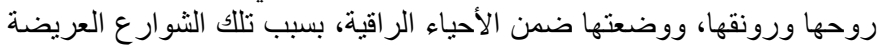

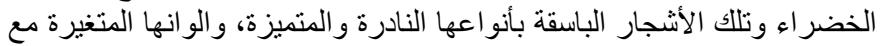

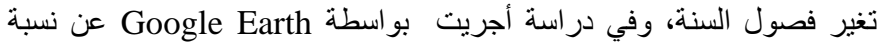

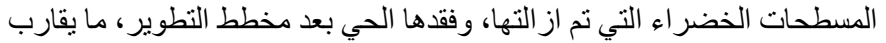

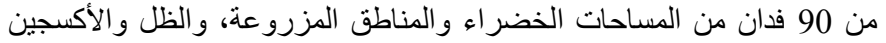

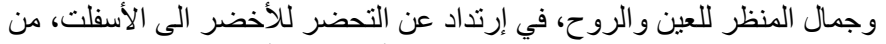

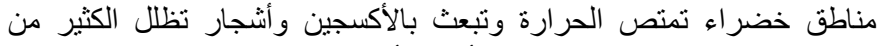

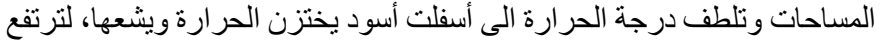
درجات الحر ارة عن ذي قبل. 
أن يكونوا من المتخصصين المعماريين و العمر انيين و الآكادميين المهتمين بموضو ع الدر اسة. حددت الدر اسة الفئة العمرية بحيث لا يقل عن 25 سنه روعي أن تكون عينة الدراسة مفتوحة و لا تقل عن 300

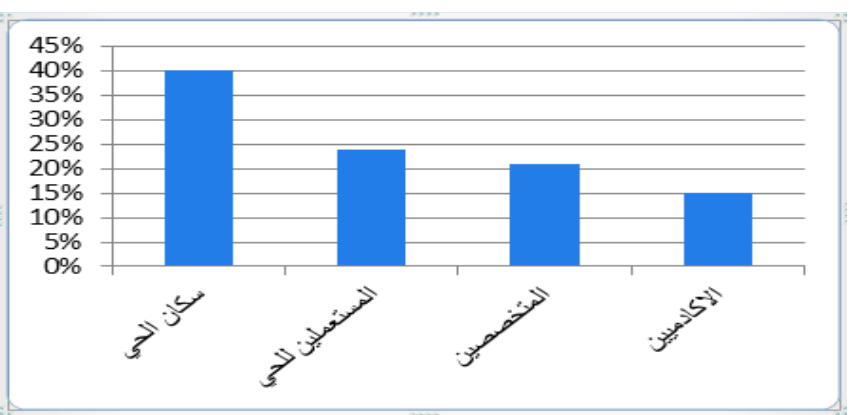

شكل (20) يوضح نسبة فئات و عدد و نو عيات عينة الدراسة

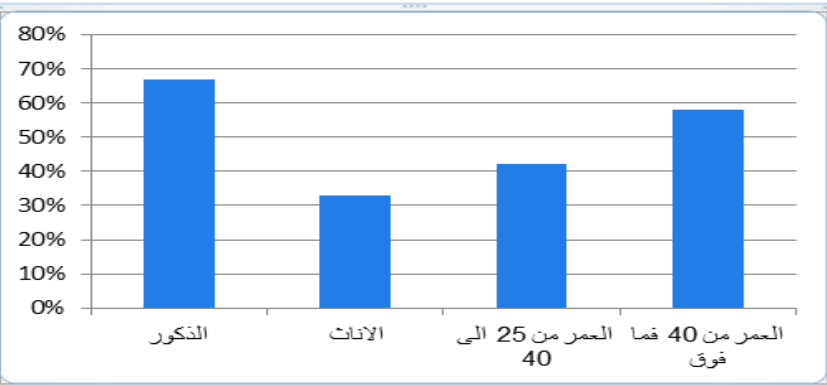

شكل (21) يوضح الفئة العمرية وجنس عينة الدراسة
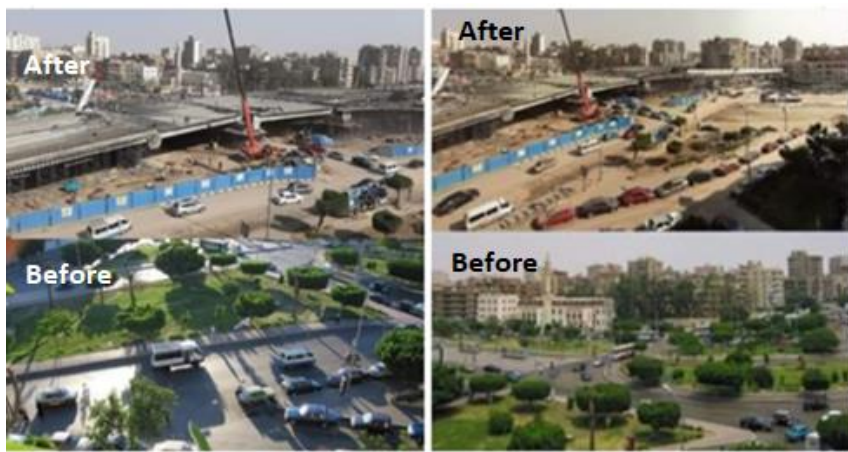

شكل (19) يوضح الثوارع و الميادين قبل و أثناءو و بعد عمليات التطوير و يتضح نسبة الحدائق المز الة و المهدرة لتوسعة وتهيئة الثنو ارع علإقامة الكباري في الثقاطعات و الميادين [28].

3-5-4-3 تقبيم الآثر البيئي والعدراني لخطة تطوبير محاور الحركة بنطقة

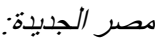

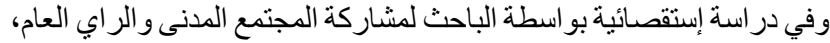

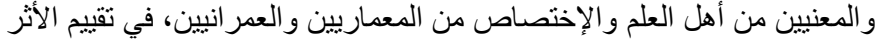

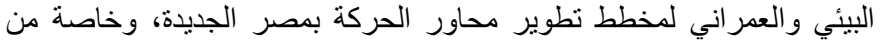

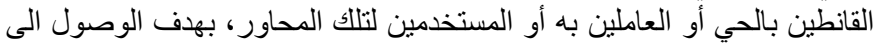

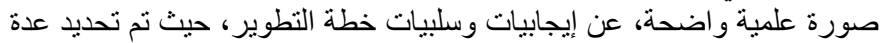

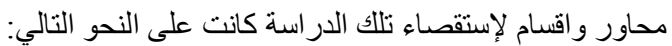

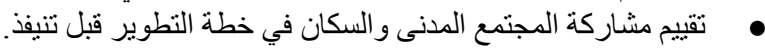

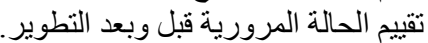

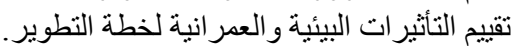

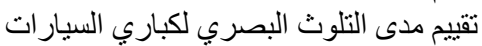
تقييم البدائل المقترحة من خلال البهن الباحث.

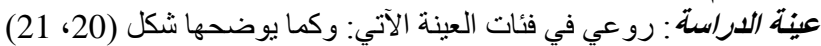

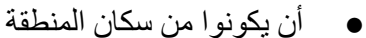
أن يكونو ا من المستعملين لمحاور المنطقة و لكن يقطنون خارجها

وفيما يلي الجداول التى توضح نتائج الدر اسة الإستقصائية : (بو اسطة الباحث)

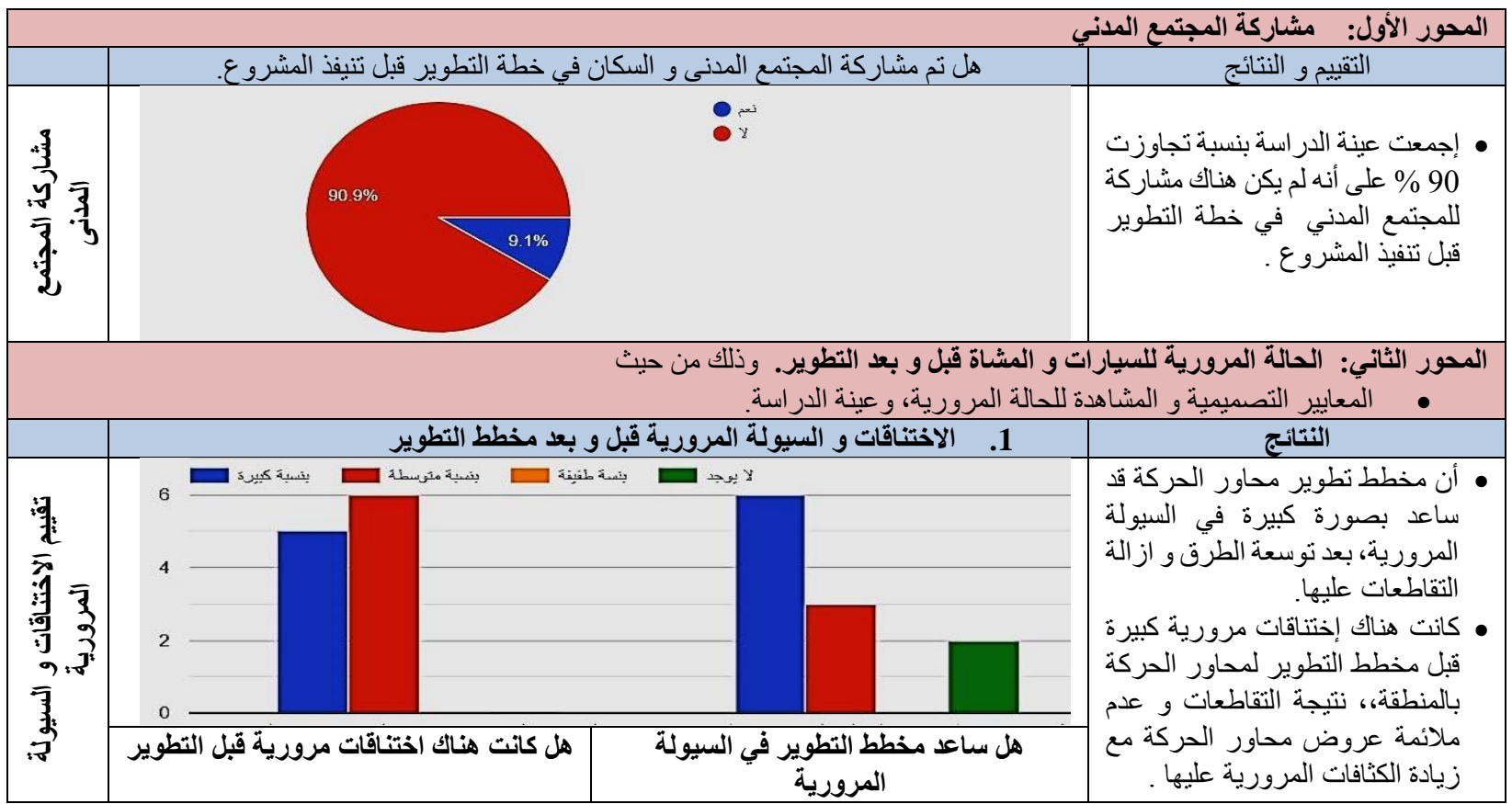



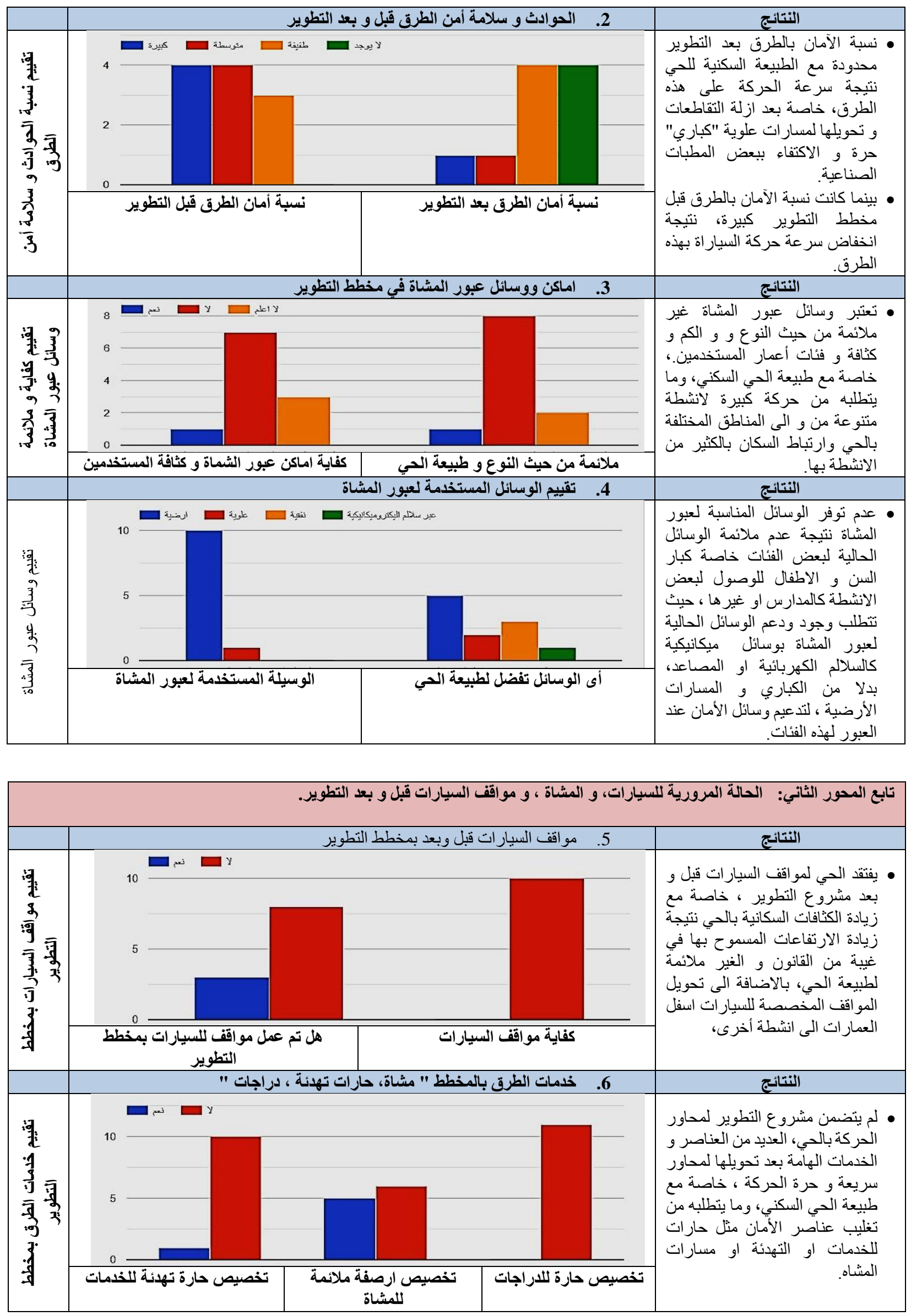


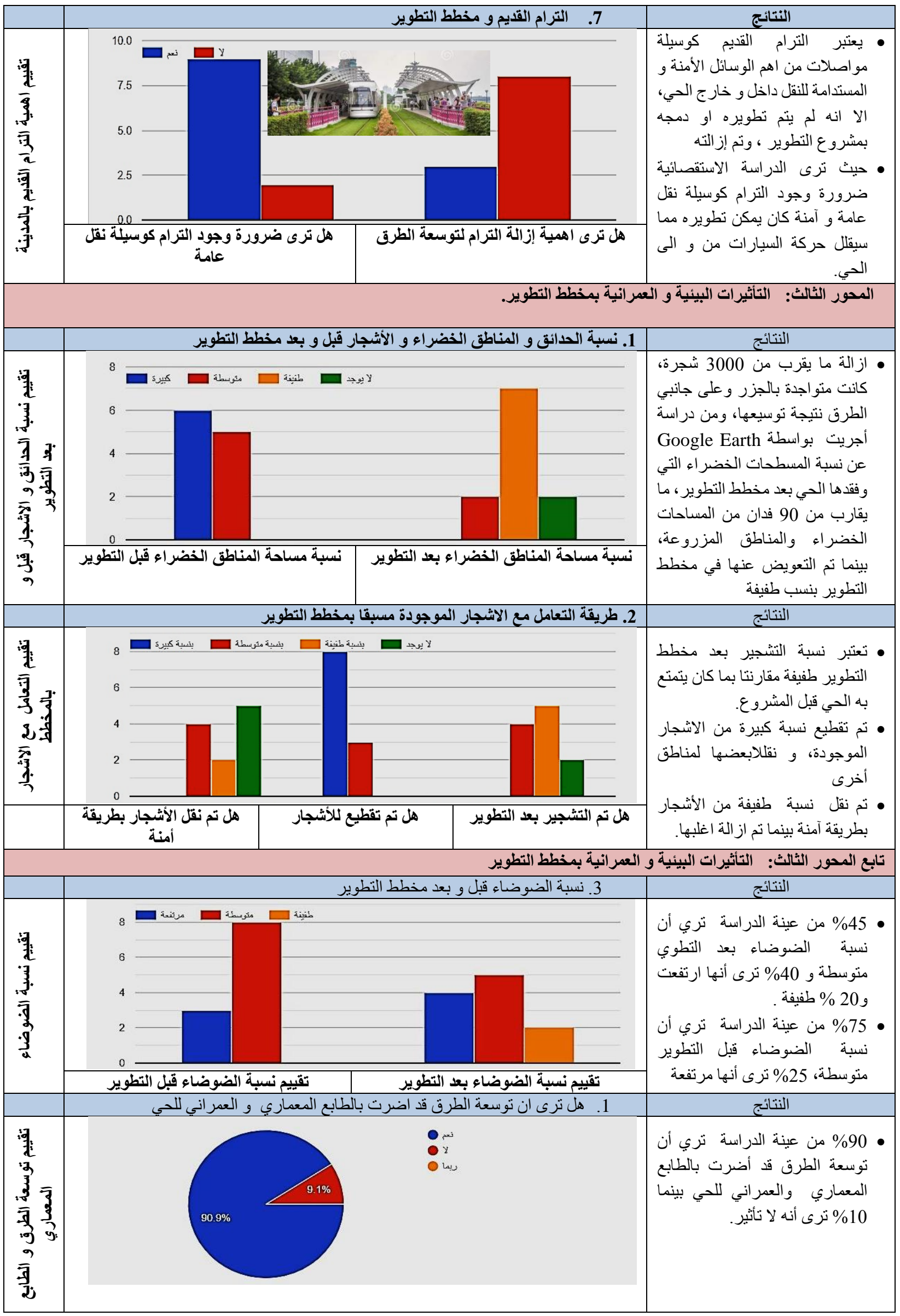




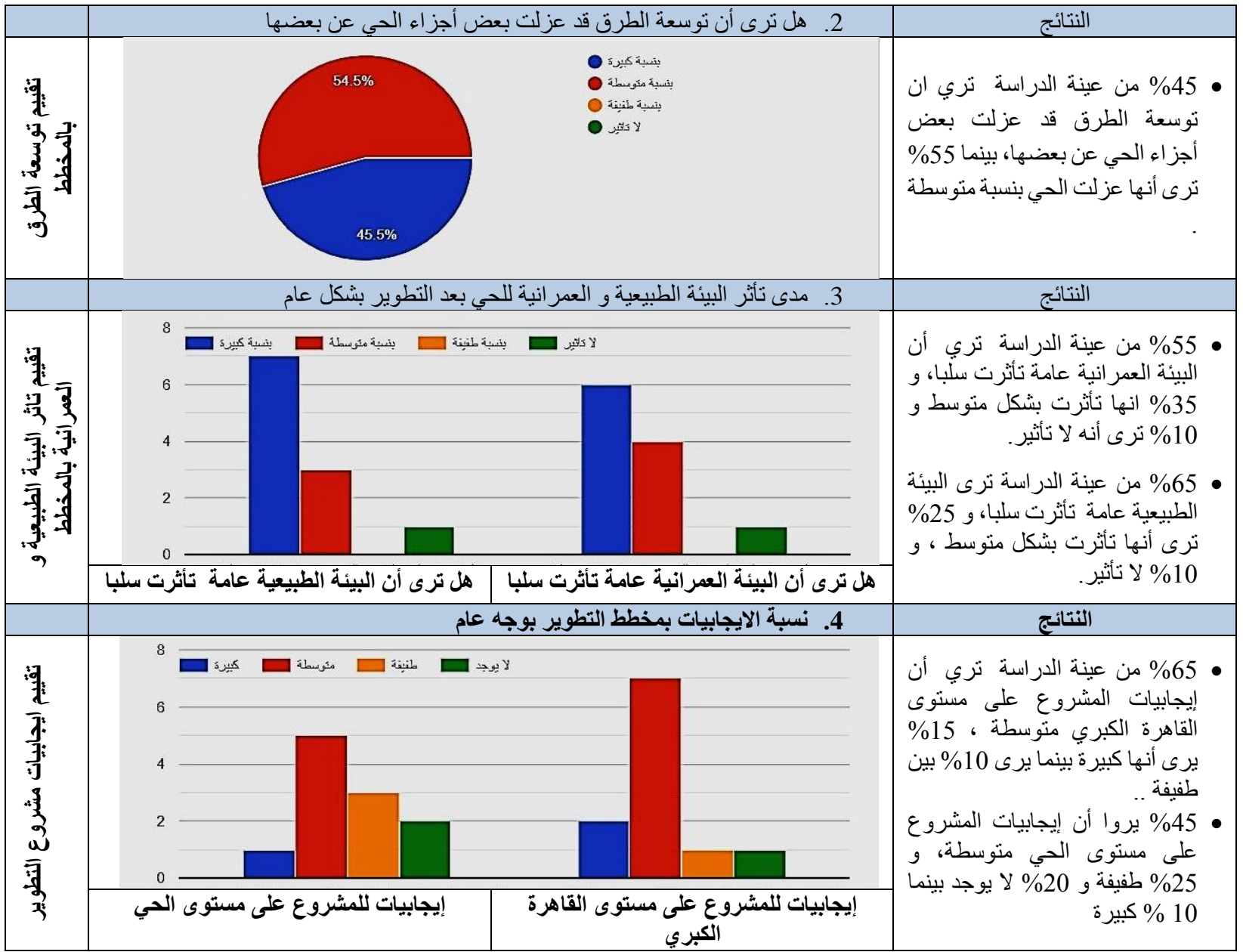

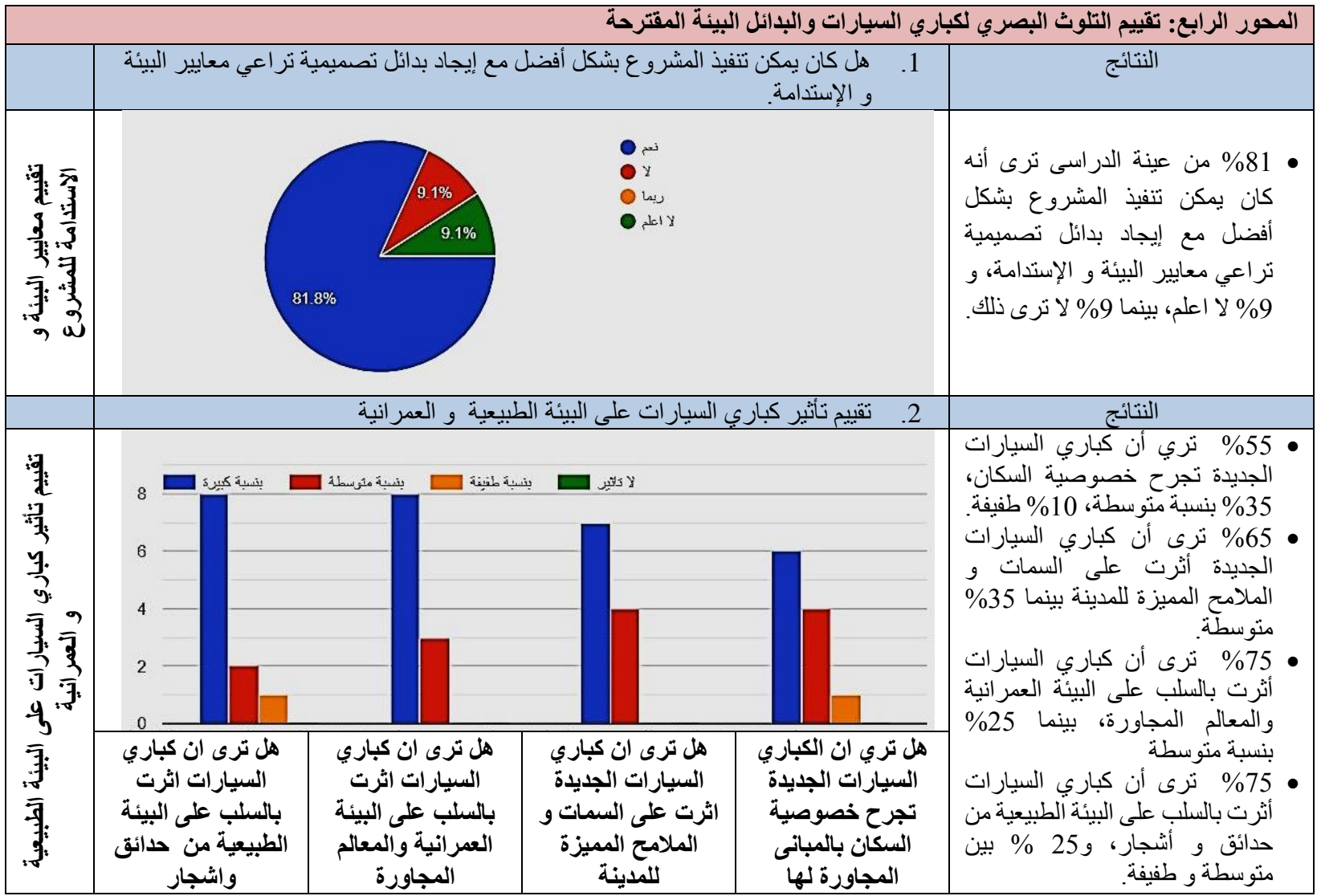




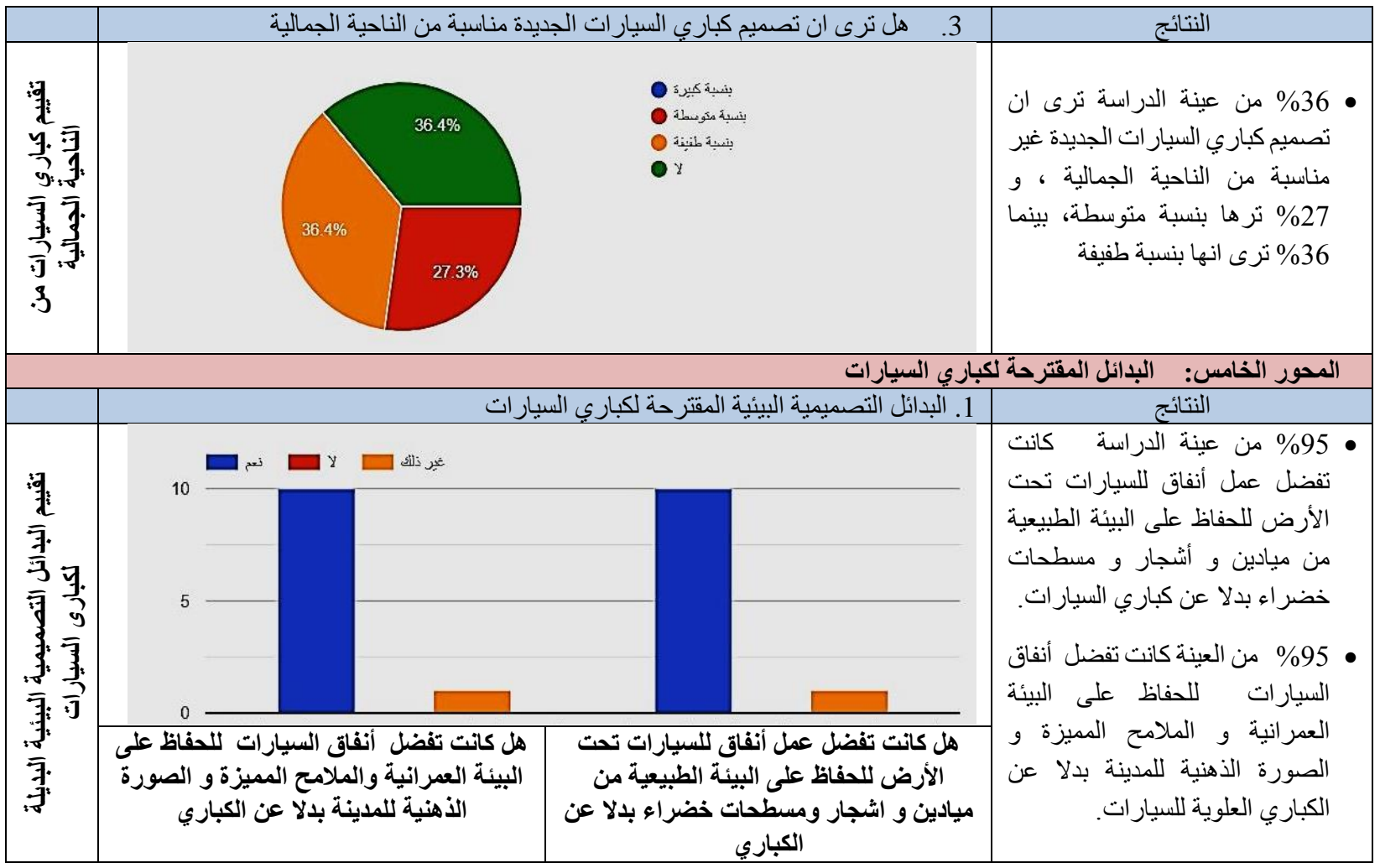

نتائج الاراسة التطبيقية

- م إن توسيع الطرق بمنطقة الدراسة و تحويلها الى طرق حرة سريعة للعبور

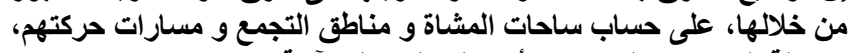

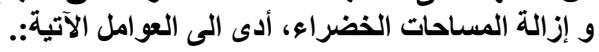

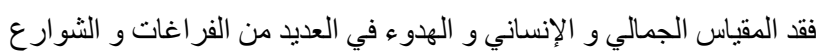

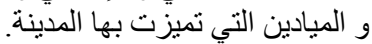

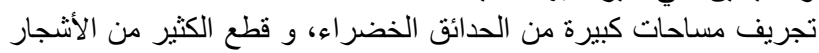

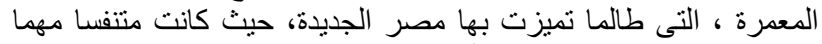
لسكان الحى و مصدرا هاما للأكسجين، مما قد يؤثر على الحياة الصحية

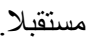
زيادة أعداد السبارات و الذي سيؤدي بدوره إلى ظهور العديد من المشاكل

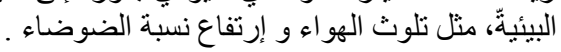

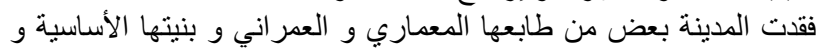
الصورة الذهنية المميزة لها.

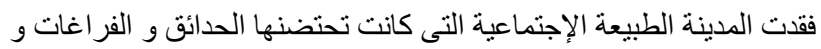

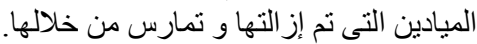

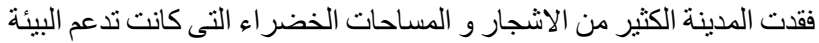

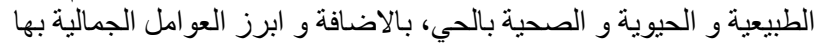

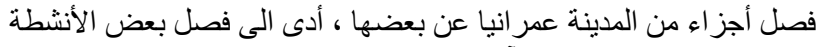

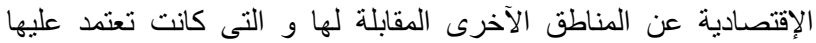

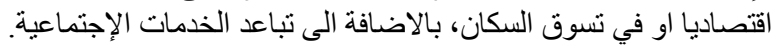

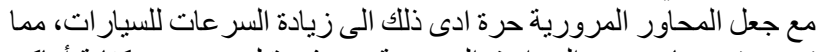
تسبب في زيادة نسب الحوادث المرورية عن ذي قبل، مع الد عدم كفاية أماكن

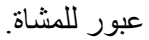

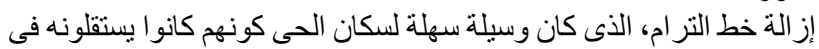
الكثير من رحلاتهم اليومية، سواء إلى العمل أو ذهاب الطلاب و الطالبات الطيات

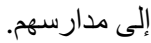
فقد الحى بعض من معالمها و ملامحه المميزة و الفراغات العامة و النسيج العمراني التى شيدها المعمارى البلجيكى البارون إمبان فى بدايات القرن

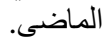
إنخفاض القيمة العقارية والإقتصادية بالحي.

\section{IV}

أصبح البعد البيئي أحد أركان التصميم و التخطيط العمر اني، وبرزت ألثئية أهمية

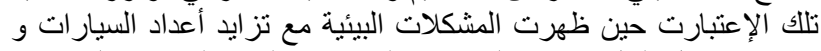

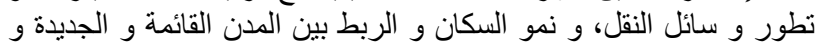

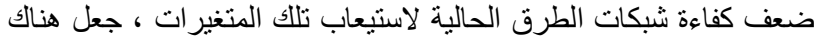

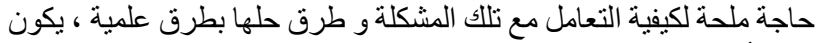
من شأنها ان تدعم الحفاظ عليها في كل من بنيتها البيئية و العمر انية.

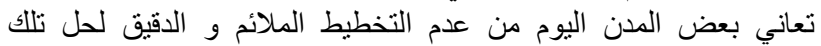

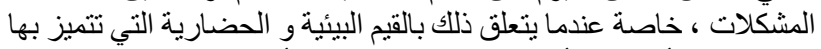

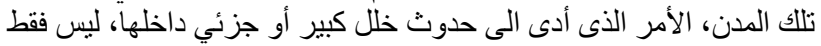

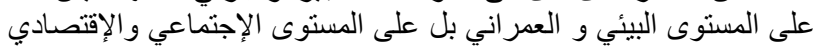
وجودة الجياة بها. هناك إعتبارت بيئية يمكن تطبيقها بالقو انين و السياسات و آليات التنفيذ، فضلا

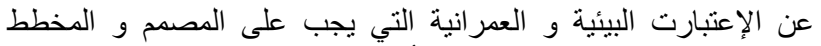

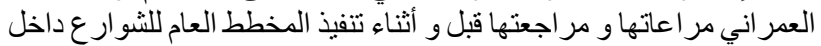

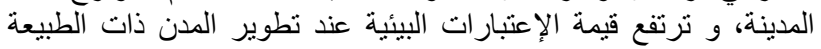

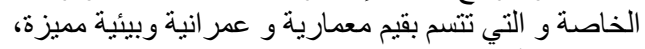

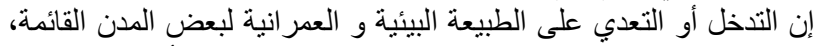

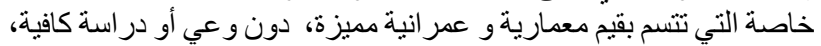

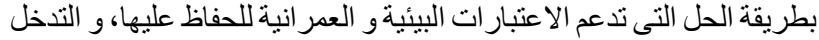

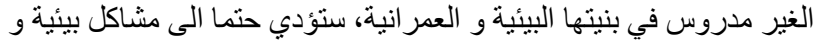
إجتماعية و صحية ونفسية حادة على قاطنى تللك المجتمعات و ربما ستؤدى لئي الى هجرنها مستقبلا. بعد جعل مدينة مصر الجديدة محور رئيسي لربط العاصمة الإدارية و الدئن

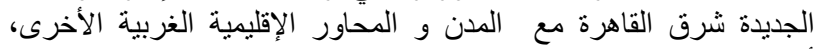

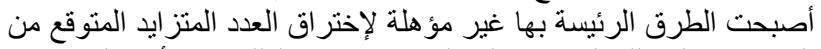

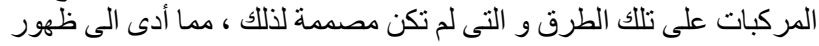
العديد من السلبيات العمر انية و البيئية والإجتماعية. 
محمود طه، "الفراغات العامة داخل النسيج العمر انى للقاهرة الكبرى"، رسالة دكتور اه، كلية

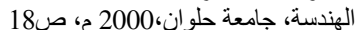

[8] Cooper Marcus \& Carolyn Francis, "People spaces - Design Guidelines for Urban Open Spaces” second edition - Van Nostrand Reinhold- New york, 1990 , p.91

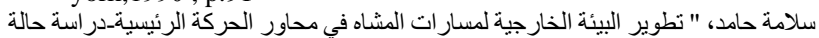

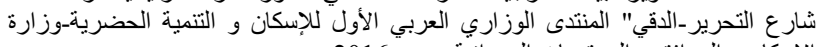

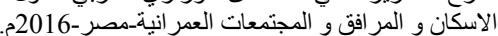

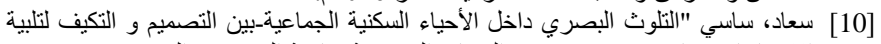

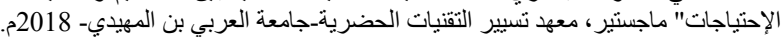

[11] La pollution visuelle: entre la conception architecturale et le mode de vie socioculturel . Cas de la cite EDIMCO - Bejaia. master en architecure, Universite de Bejaia , 2016.

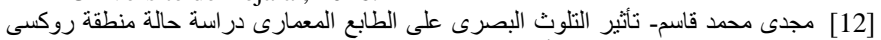

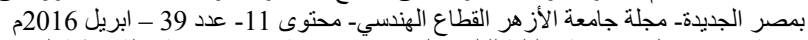

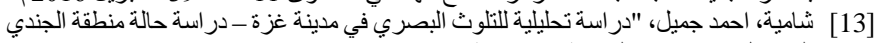

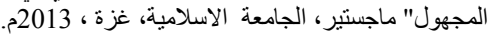

[14] https://www.almasryalyoum.com/news/details/1443781 وجيه و هبةـ بين قاهرتين، الأحد 17-11-2019 - تم الاطلاع في 20-2020-2020.

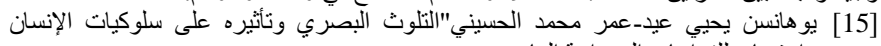
و إستيعابه للفر اغات العمر انية العامة.

[16] https://ar.wikipedia.org/wiki/\%D8\%AD\%D9\%8A_\%D9\%85\%D8\%B5 $\% \mathrm{D} 8 \% \mathrm{~B} 1(13)$

[17] https://aawsat.com/home/article/2095131/.

عبد الفتاح فرج - حي الرؤساء الرافي يفتقد ملامحه - 23 يناير 2020 مـ رقم العدد 15031- تم

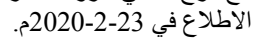

[18] https://www.almasryalyoum.com/news/details/1440877:23 -

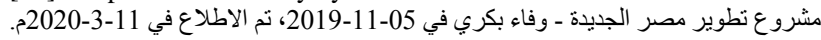

[19] https://www.copts-united.com/Article.php?I=3981\&A=533712

أخبار مصرية- 22 يناير 2020 "9 اسباب لتطوير محاور مصر الجديدة" تم الاتطلاع في 20-20-

[20] https://www.youm7.com/story/2020/2/4/

2020

سيد الخلفاوى - 04 فبر اير 2020 11:47 ص"شاهد كبارى مصر الجديدة بعد انتهاء تنفيذها" تم

[21] https://www.oirealtor.com/noticias-inmobiliarias/en/barcelona-gainsground-with-plaza-de-glories/ Barcelona gains ground with Plaza de Glòries, BY MIRIAM 8 JULY 2015 on May, 1, 2020.

[22] https://meet.barcelona.cat/ca/descobreix-barcelona/districtes/santmarti/placa-de-les-glories on May 1, 2020

[23] https://espanarusa.com/en/hedonist/ad/hedonist/categories/Soul/squares/ 499582\#prettyPhoto

[24] https://advice.aqarmap.com.eg/ar/heliopolis-from-inception-untilcultivation-bridges/ 23 - مارس 2020

[25] https://aawsat.com/home/article/2095131/

عبد الفتاح فرج - الخميس - 23 يناير 2020 مـ رقم العدد [ 15031- تم الاطلاع في 17-2020-2020م.

[26] https://www.shorouknews.com/news/view.aspx?cdate=16022020\&id=e 333bddb-5fa4-403a-861d-43cd1c7891fa

شريف حربى ومحمد عبدالناصر عنوان المقال - مخطط نطوير مصر الجديدة.. بين انسيابية المرور وفقدان ملامح الحى الر اقىـ نشر فى : الأحد 16 فبر اير 2020 - 8:57 مـ تم الاطلاع في 215 215 2020-3

[27] https://www.shorouknews.com/news/view.aspx?cdate=29022020\&id=9 f9ef8c2-2497-44b8-9a4e-67f9e468ba28

شريف حربى:نشر فى : السبت 29 فبراير 2020 - 7:59 م | آخر تحديث : 1 مارس 2020م- تم

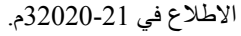

[28] https://www.facebook.com/HeliopolisHeritageInitiative "Heliopolis Hirtage Initiative"

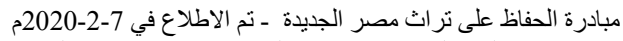

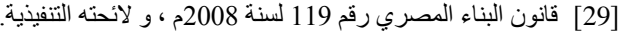
[30] ] قانون البيئة المصري رقم البنم 4 لسنة 1994م ، و لائحته التنفيذية.

[31] https://www.youm7.com/story/2019/11/4/

مصر تقفز 90 مركزا فى الترتيب العالمى لمؤشر جودة الطرق خلال 5 سنوات..إنفوجر اف الإثنين، 04 نوفمبر 2019 03:34 مسنات

[32] http://www.impactlab.net/2015/09/25/mexico-city-to-turn-10-lanehighway-into-a-park/-Mexico City to turn 10-lane highway into a park. 2020-9-5 الاطلاع في

[33] https://www.pinterest.com/ong_kantiya/urban-road/ --9-5 في الاطلاع في 2020 2020

[34] https://egypt14.com/2015/04/11/2020-6-20 - ما هي مخاطر زحمة في في في المرور علي صحتك؟

2020-2-15 الاطلاع في 2020 - 20
التلوث البصري الناتج عن قطع الإمتداد البصري للكباري لبعض المعالم و

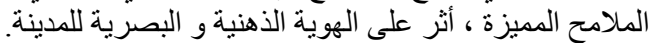

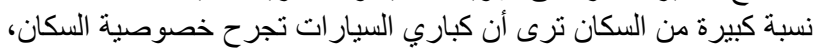

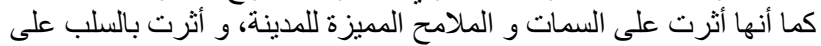

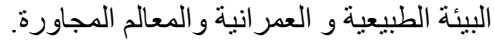

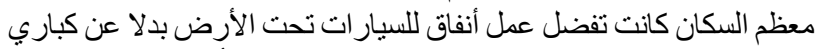

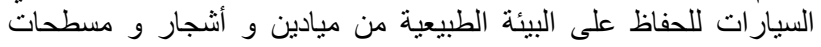

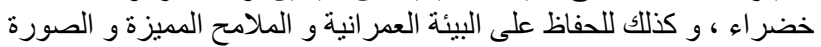
الذهنية للمدينة.

\section{التوصبات}

توصيات تتعلق بتحسين الوضع الراهن بعد تتفيذ المشروع لرفع الكفائة البيئية و

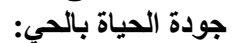

تعظيم المساحات الخضر اء ما أمكن و التشجير بأنو اع أشجار ذات خصائص تظليل أفقية يمكن من خلالها تحسين الرؤية البصرية وتخفيض معن معدل

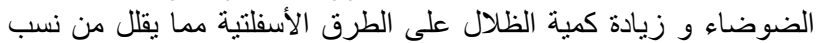

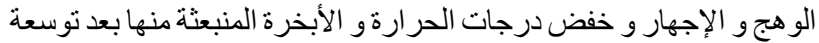

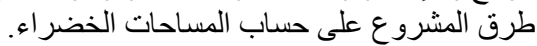
الحد من الأثار السلبية الناتجة عن الحفئية الحلول التخطيطية و العمرانية الغير مدروسة، عند تطوير محاور الحركة القائمة. توجيه نظر المعنيين بشئون العمران و القائمين على تطويره بأهمية الحلول

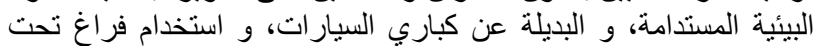
الارض كأحد الحلول الهامة للحفاظ على البيئة الطبيعة و العمر انية و الطابع

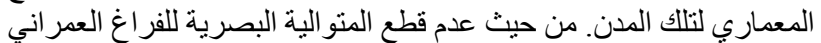
و الحفاظ على التتابع البصري لها، و الحفاظ على الصورة الذهن الذهية للمدينة.

إعادة النظر في التصميم العدرانسي للعناصر التصمبية الناصة بالطرق و خاصة

عمل حار ات للخدمات للتهدئة مما يقلل من الحوادث خاصة بعد ما أصبحت

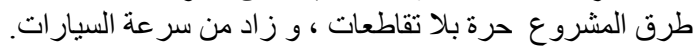

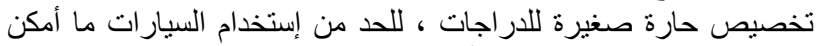

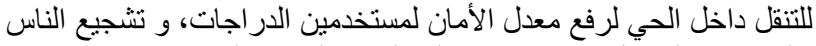

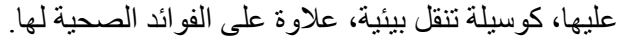

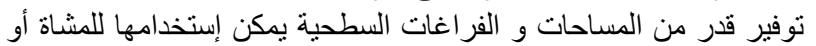
الأنشطة الإجتماعية ، و الإبقاء عن على الإتصال الإجتماعي و الأنثطة

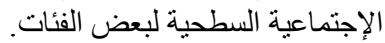

الإبقاء على الإتصال بين أجزاء المدينة عمرانيا، وذلك بعمل أماكن كافية

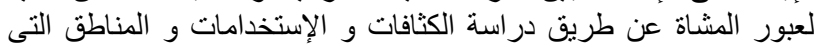

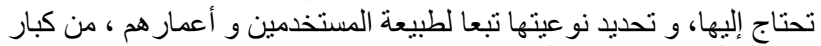

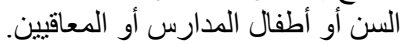

عمل مو اقف للسيار ات تستو عب الكثافات السكانية لتعالج السلبيات السابقة في السماح للبعض بالبناء و زيادة الإرتفاعات دون الأخذ في الإعتبار إشتر اطات

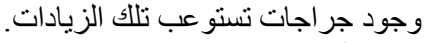

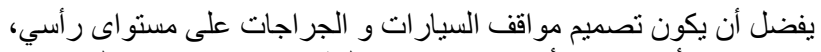

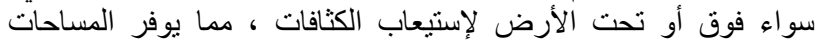
السطحية للمسطحاث الخضر اءو أو الأنشطة الإجتماعية الأخرى.

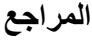

محمد، صباح محمود ، "المدخل في تخطبط النقل الحضري " ، ط1 ، مطبعة الوراق ، عمان ، 2003م. التحبي.

النلامي، وفاء جبر "الاعتبار ات البيئية و أثر ها في مشكلة النقل و المرور في المدينة: مجلة كلية

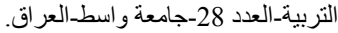
رسول ، أحمد حبيب ، العدد درامعة واسطـات في جغرافي افيا النقل ، دار النهضة العربية للطباعة ، بيروت ،

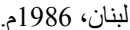

عبده، سعيد ، جغر افية النقل "مغز اهاو مرماها" ، مكتبة الانجلو المصرية ، القاهرة ، مصر ، 1994م.

Stones, Tabor R., Beyond the Automobile - Prentice Hall, Inc., N. p46. ‘ J1992

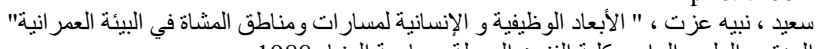
المؤتمر العلمي الر ابع، كلية الفنون الجميلة ، جامعة المنيا، 1988م. الإنية 
الإجتماعي والإقتصادي وجودة الجياة بها، هذا بالإضافة لحدوث إضطر ابات نفسية وصحية

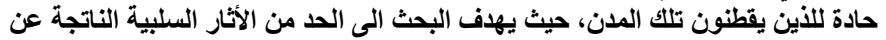

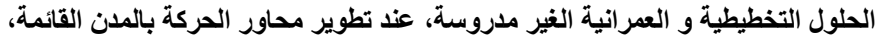

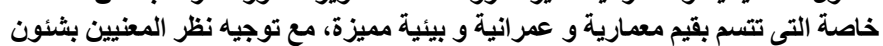

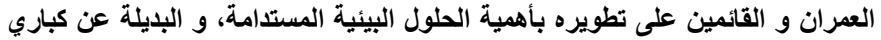

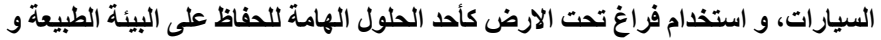

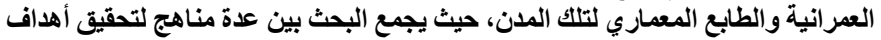

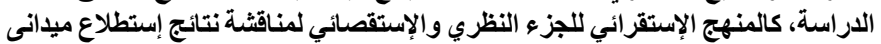

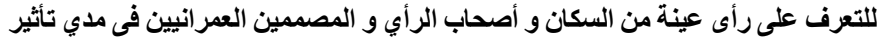

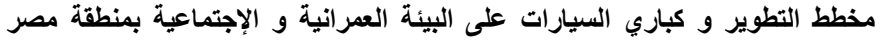
الجديدة، و قياس مدى إيجابيات و سلبيات المخطط الجديا.

\section{Title Arabic:}

تقييم الأثر البيئي والعمراني لمخطط تطوير محاور الحركة لمنطقة مصر الجديدة

\section{Arabic Abstract:}

يعد نمو السكاني و العمراني من أهم مظاهر الحضارة الحليثة، و قد بدأ هذا النمو بنشاط

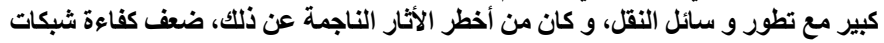

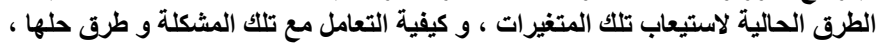

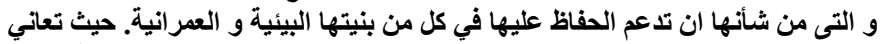

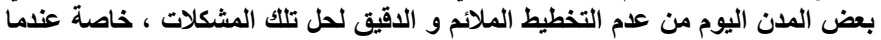

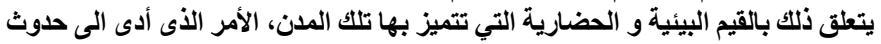

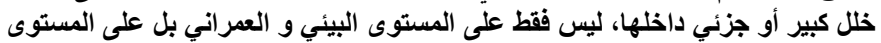

